SERVIÇO DF POS-GRADUAÇNOO DO ICMC-USP

Data de Depósito: $\quad 22.02 .2002$

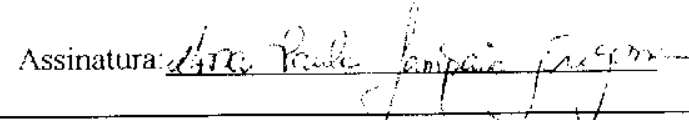

\title{
Uma avaliação de meta-heuristicas para o problema de designação quadrática
}

\author{
Thiago D'Martin Maia
}

Orientadora: Profa. Dra. Regina Esther Berretá

Disscrtação apresentada ao Instituto de Ciências Matcmáticas e de Computação - ICMC -USP. como parte dos requisitos para obtenção do título de Mestre em Ciências de Computação c Matemática Computacional.

USP - São Carlos

Fevereiro/2002 


\section{A Comissão Julgadora:}

Profa. Dra. Regina Esther Betretra

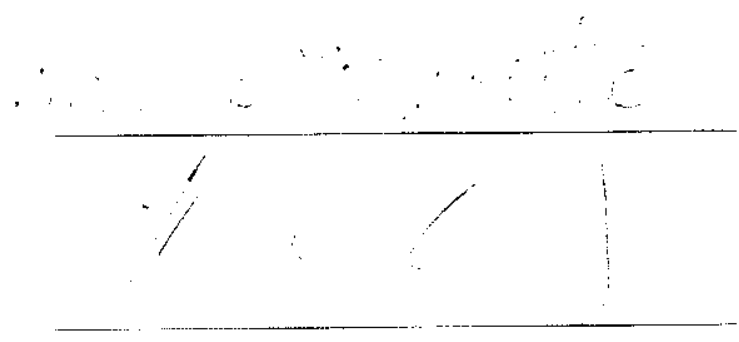

Prof. Dr. Marcos Nercu Arenales

Profa. Dra. Dihora Preni Ronconi

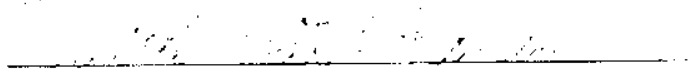


Para Regina, que me considerou factivel e procurou melhorar-me. 
À minha família, com admiraçào;

Aos meus amigos todos;

A Marcos Nereu Arenales, Maria das Graças Volpe Nunes, Pablo Alberto Moscato, Reinaldo Morabito Neto, Nair Maria Maia de Abreu, Vitória Maria Miranda Pureza, Roseli Aparecida Francelin Romero, Edna Maura Zuffi, Renata Pontin de Mattos Fortes, Luiz Fernando Rodrigues e Luciana Salete Buriol, que me permitiram espiar seu conhecimento vasto;

Aos funcionários da USP;

Ȧ agência CAPES, que financiou o projeto;

Ao Estado de São Paulo; e

A João Ubaldo Ribeiro, pela cessão da epígrafe. 
Sabe-se muito pouco.

João Ubaldo Ribeiro, em O Feitiço da Ilha do Pavão 


\section{RESUMO}

Este trabalho apresenta uma avaliação de meta-hcurísticas para a resolução do Problema de Designação Quadrática (Quadratic Assignment Problem).

O Problema de Designação Quadrática consiste $\mathrm{cm}$ posicionar-se um determinado conjunto de instalações em um determinado conjunto de localidades, dados os fluxos entre as instalações e as distâncias entre as localidades, com o objetivo de minimizar um somatório que vincula os fluxos às distâncias de acordo com o posicionamento.

Foram implementadas heurísticas que utilizam Busca Tabu, Algoritmos Genéticos e Algoritmos Meméticos, $\mathrm{e}$ uma avaliação com exemplos numéricos encontrados na literatura foi realizada. 


\begin{abstract}
This work presents an evaluation of metaheuristics for the Quadratic Assignment Problem. The Quadratic Assignment Problem consists of assigning a set of facilities (with given flows between them) to a set of locations (with given d'stances between them), in such a way that the sum of the product between flows and distances is minimized.

Heuristics using Tabu Search, Genetic Algorithms and Memetic Algorithms have been implemented, and it was done an evaluation with instances found in literature.
\end{abstract}


2. PROBLEMA DE DESIGNAÇÃO QCADRÁTICA - QAP …...............................................................11

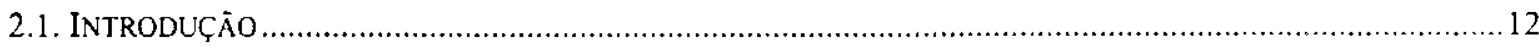

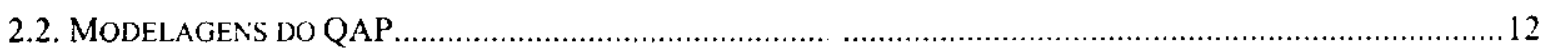

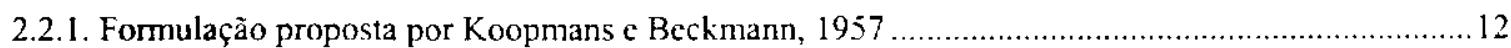

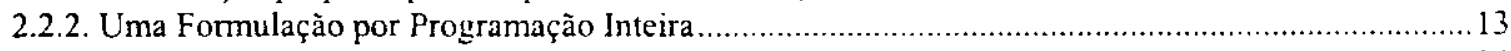

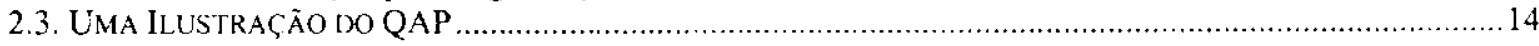

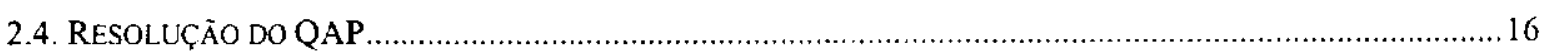

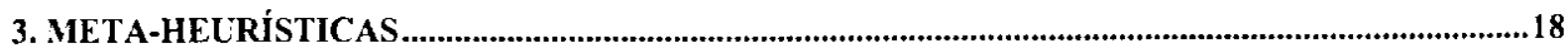

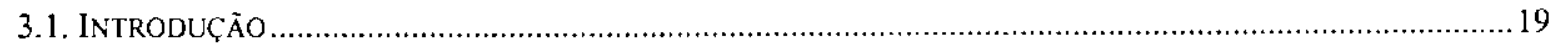

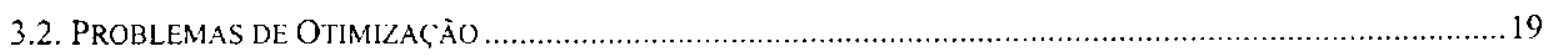

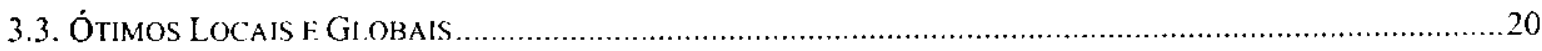

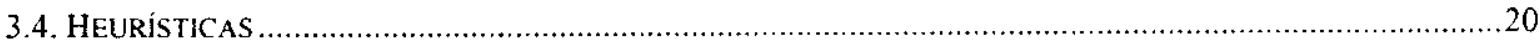

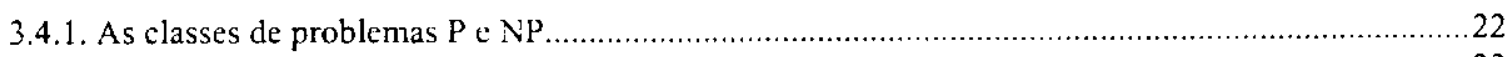

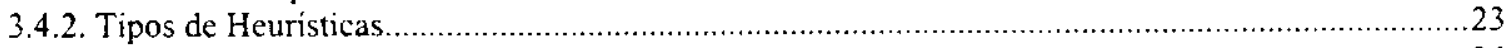

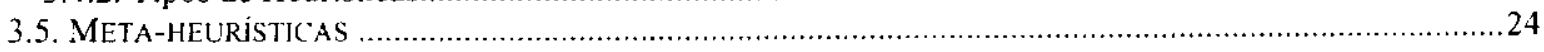

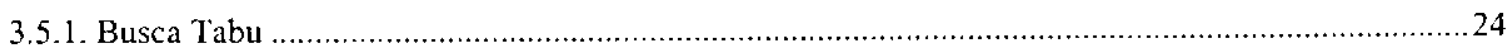

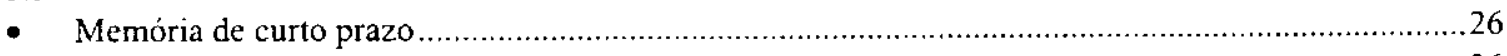

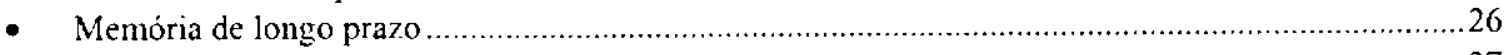

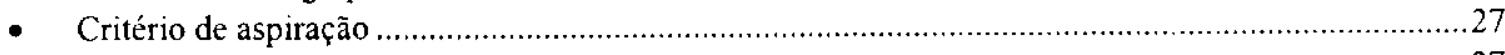

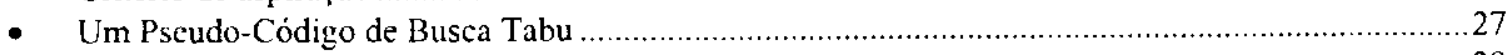

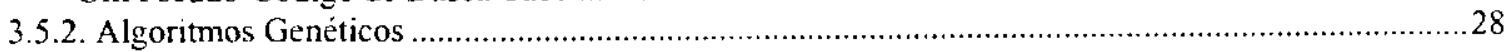

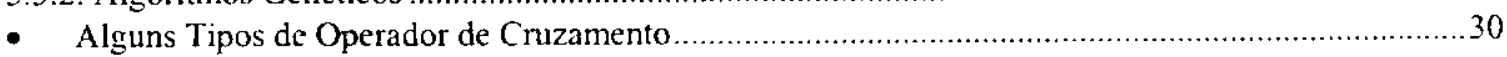

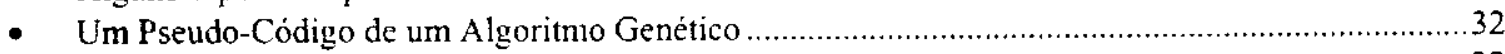

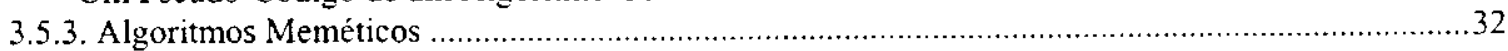

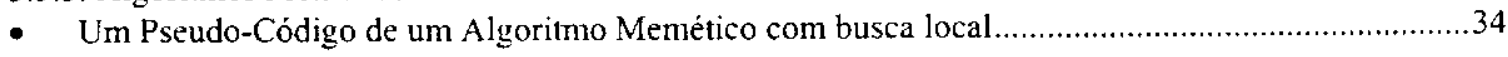

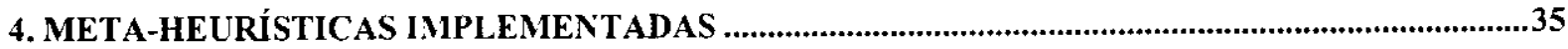

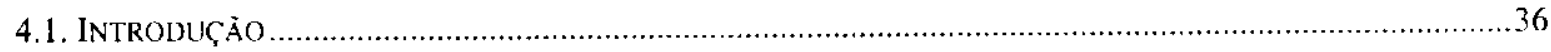

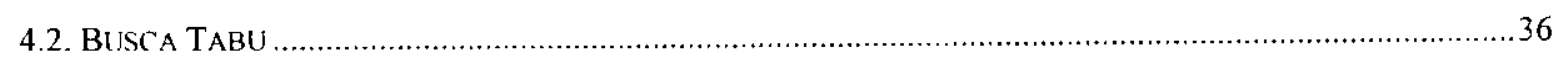

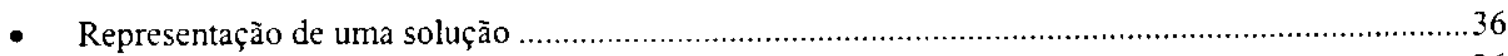

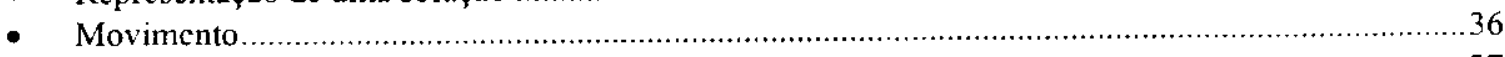

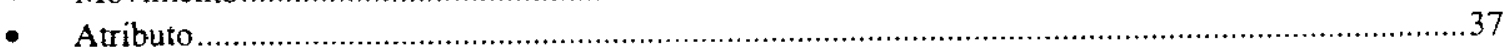

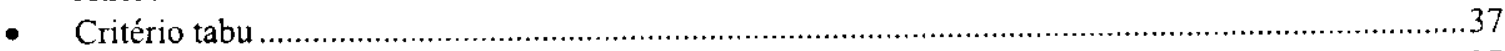

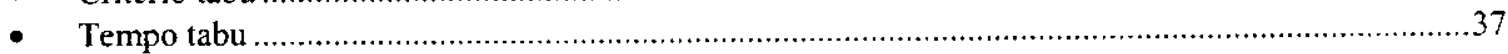

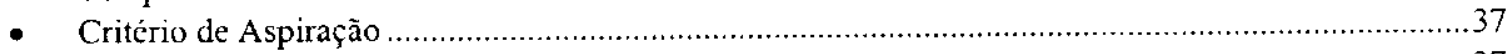

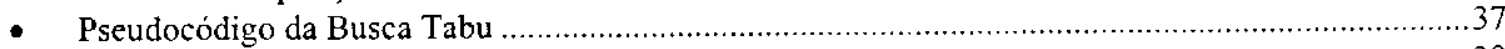

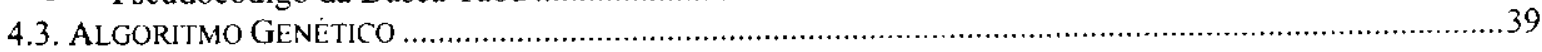

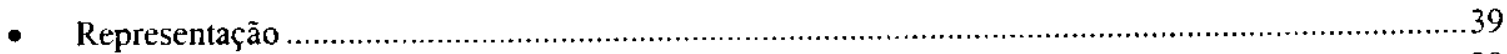

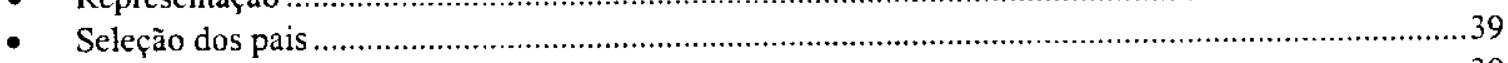

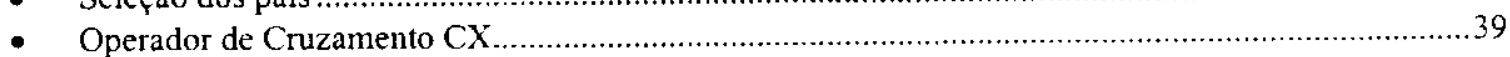

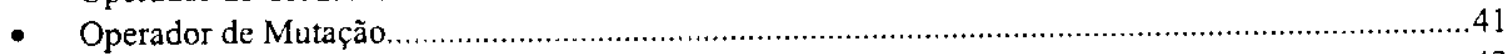

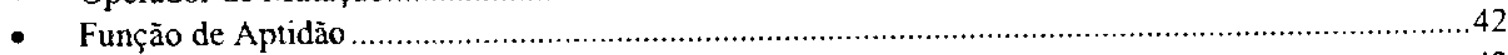

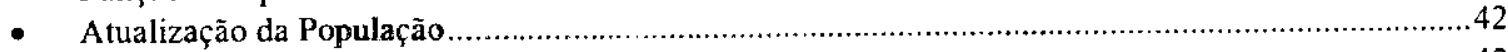

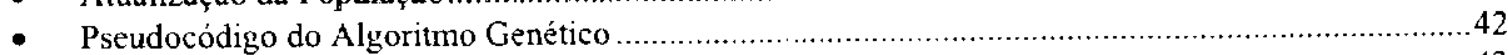

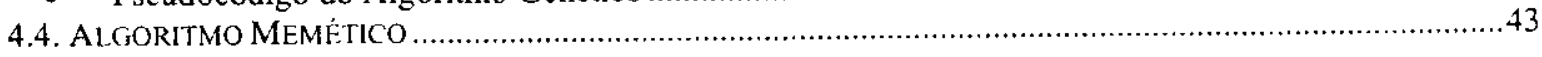

- Pseudocódigo do Algoritmo Memético …………........................................................................44 


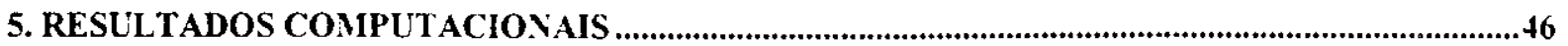

5.1. INTRODUÇ̃̃O

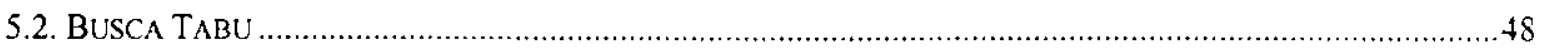

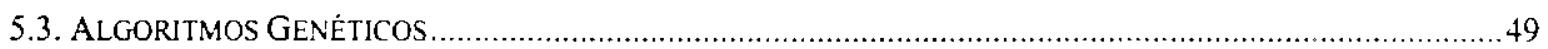

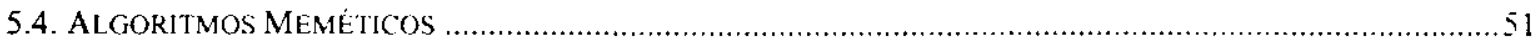

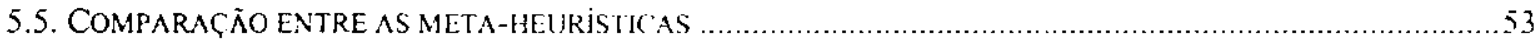

6. CONCLUSÃO

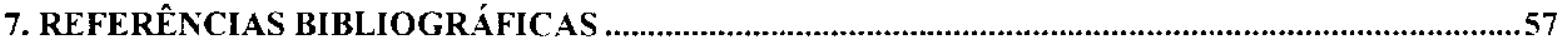


1. INTRODUÇÃO 
Esse trabalho apresenta uma avaliação de algumas técnicas meta-heurísticas para a resolução do Problema de Designação Quadrática (QAP).

O QAP pode ser definido, sucintamente, como a necessidade de se otimizar a designação de um certo conjunto de instalações, entre as quais são dados os fluxos, a um certo conjunto de localidades, entre as quais sào dadas as distâncias.

Para tal problema ainda nāo se conhece um algoritmo eficiente que apresente resolução exata. Essa dificuldade o classifica como NP-dificil.

Como principal objetivo do trabalho, serão avaliadas algumas técnicas computacionais chamadas Meta-heurísticas na resolução do QAP. Estas vêm sendo largamente pesquisadas e utilizadas com sucesso na resolução de problemas classificados como difíceis em Otimização.

O texto é organizado da seguinte forma: após esta introdução há uma apresentação detalhada do QAP, usando-se definições clássicas encontradas na literatura, exemplos gráficos e a descrição de caminhos considerados promissores na resolução dessc problema. O terceiro capítulo introduz o conceito de Meta-heuristicas, algoritmos que foram avaliados para a resolução do QAP. São ainda abordadas especificamente algumas dessas estratégias metaheurísticas. No quarto capítulo são descritas em detalhes as meta-heurísticas implementadas, e no quinto são analisados os resultados computacionais obtidos. Em seguida são apresentadas as conclusões a que se chegou. Finalmente são citadas as referências bibliográficas. 
2. PROBLEMA DE DESIGNAÇÃO QUADRÁTICA - QAP 


\subsection{Introdução}

O Problema de Designação Quadrática (ou QAP, de Quadratic Assignment Problem) consiste em encontrar o posicionamento ótimo em casos de designação de instalações a localidades pré-definidas, levando-se em conta as distâncias entre as localidades e os níveis de interação entre as instalações. Os termos instalação e localidade devem ser entendidos num grau abstrato e não no sentido normalmente usado, devido à grande quantidade de elementos da realidade que podem assumir essas denominaçòes.

Vários problemas reais e de importância atual podem ser modelados como um QAP. Dentre estes, problemas de localização de fábricas ou máquinas, projetos arquiteturais (Elshafei, 1977, Gero et al., 1997) e projetos de eletrônica (Junger et al., 1994). Além disso, problcmas clássicos de Otimização como o Problema do Caixeiro Viajante e o Problema de Partição de Grafos podem ser vistos como casos específicos do QAP (Dell'Amico et al., 1997).

Uma motivação adicional para a pesquisa e o desenvolvimento de técnicas para a resolução do QAP é o fato de que este problema faz parte da classe NP-difícil (Garey and Johnson, 1979). Tal classe é composta de problemas para os quais é improvável a cxistência de um algoritmo eficiente que os resolva exatamente.

A seguir, são apresentadas algumas formulações do QAP.

\subsection{Modelagens do QAP}

\subsubsection{Formulação proposta por Koopmans e Beckmann, 1957}

Koopmans e Beckmann, 1957, introduziram o QAP como a designação de um determinado conjur.to de instalações (fábricas, por exemplo), entre as quais são conhecidos os fluxos, a um determinado conjunto de localidades, entre as quais são conhecidas as distâncias. O objetivo é então minimizar um somatório que vincula os fluxos às distâncias. A formulação proposta por Koopmans e Beckmann, 1957, pode ser descrita como a seguir: 
Sejam:

n - número de instalações ou localidades;

$V(n)$ - o conjunto de todas as permutações de $\{1,2, \ldots, n\}$;

$A\left(a_{i j}\right)$-uma matriz nxn, onde $a_{i j}$ representa o fluxo de materiais da instalação i para a $j$;

$\mathrm{B}\left(\mathrm{b}_{\mathrm{k} l}\right)$ - uma matriz nxn, onde $\mathrm{b}_{\mathrm{k} l}$ representa a distância entre as localidades k e l.

O objetivo é minimizar a função

$$
C(v)=\sum_{i=1}^{n} \sum_{j=1}^{n} a_{i j} b_{v(i) v(j)} \quad v \in V(n)
$$

O objetivo é posicionar $\mathrm{n}$ instalações que produzam diferentes produtos, levando-se em conta que os produtos originados em uma dessas instalações poderão ser insumos para as demais e vice-versa. Haverá então fluxos de transporte e comunicação entre as mesmas. É razoável portanto imaginar que instalações que interagem muito entre si devam ser posicionadas em localidades mais próximas umas das outras. Dessa maneira, se as instalações i e $\mathrm{j}$ forem posicionadas nas localidades $\mathrm{k}$ e $\mathrm{l}$, respectivamente, é natural que o custo dessa atribuição seja o produto do fluxo entre as instalações pela distância entre as localidades, desde que se considerem os custos de transporte proporcionais às distâncias percorridas. Assim, minimizar a função objetivo dada pelo somatório do produto dos fluxos pelas distâncias (1) é determinar uma permutação de instalações sobre localidades, de tal forma que esse somatório seja o menor possível. O processo de minimização deve levar em conta que as distâncias entre as localidades e os fluxos entre as instalações são dados, e portanto a estratégia a ser seguida deve posicionar os pares de instalações com maior fluxo nos pares de localidades que distem menos entre si - observando o comportamento da função objetivo pelo uso das permutações. Em outras palavras, nessa formulação a decisão está presente na fase de permutações, escolhendo-se no conjunto $\mathrm{V}$ aquela que fará o sistema resultar num posicionamento ótimo.

\subsubsection{Uma Formulação por Programação Inteira}

Uma maneira de modelar-se o QAP é como um problema de Programação inteira, descrito a seguir (Nemhauser e Wolsey, 1988). 
Sejam:

m - quantidade de instalações;

$\mathrm{n}$ - quantidade de localidades (com $\mathrm{m} \leq \mathrm{n}$ );

$C_{i j}$ - o volume transportado da instalação i para a instalação $j$, ou seja, o fluxo de insumos provenientes da instalação i para a instalação $j$;

$D_{k l}$ - o custo de transporte de insumos da localidade $k$ para a localidade 1 , ou seja, a distância entre essas duas localidades, levando-se em conta que os custos de transporte sejam proporcionais às distâncias percorridas.

Seja a seguinte variável de decisão:

$\mathrm{X}_{\mathrm{ik}}=1$ se a instalação $\mathrm{i}$ estiver posicionada na localidade $\mathrm{k}$;

0 caso contrário.

Temos assim a seguinte formulação:

$$
\min \sum_{\substack{i, j=1 \\ i \neq j}}^{\mathfrak{n}} \sum_{\substack{k, l=1 \\ k \neq 1}}^{m} C_{i j} \cdot D_{k !} \cdot X_{i k} \cdot X_{j !}
$$

Sujeito a:

$$
\begin{array}{ll}
\sum_{i=1}^{m} X_{i k} \leq 1 & k=1, \ldots, n \\
\sum_{k=1}^{n} X_{i k}=1 & i=1, \ldots, m \\
X_{i k} \in\{0,1\} &
\end{array}
$$

$\mathrm{Na}$ formulação acima, o conjunto de restrições (3) garante que cada localidade é designada a no máximo uma instalação, e (4) garante que toda instalação é designada a uma localidade. Note que nessa formulação o número de instalações e localidades pode ser diferente $(m \leq n)$. Em geral, na literatura sobre QAP considera-se que $m=n$.

\subsection{Uma llustração do QAP}

A seguir é apresentado um exemplo simples do QAP. São 5 localidades, 3 instalações e 3 fluxos de insumos entre as mesmas (Figura 2.1): 

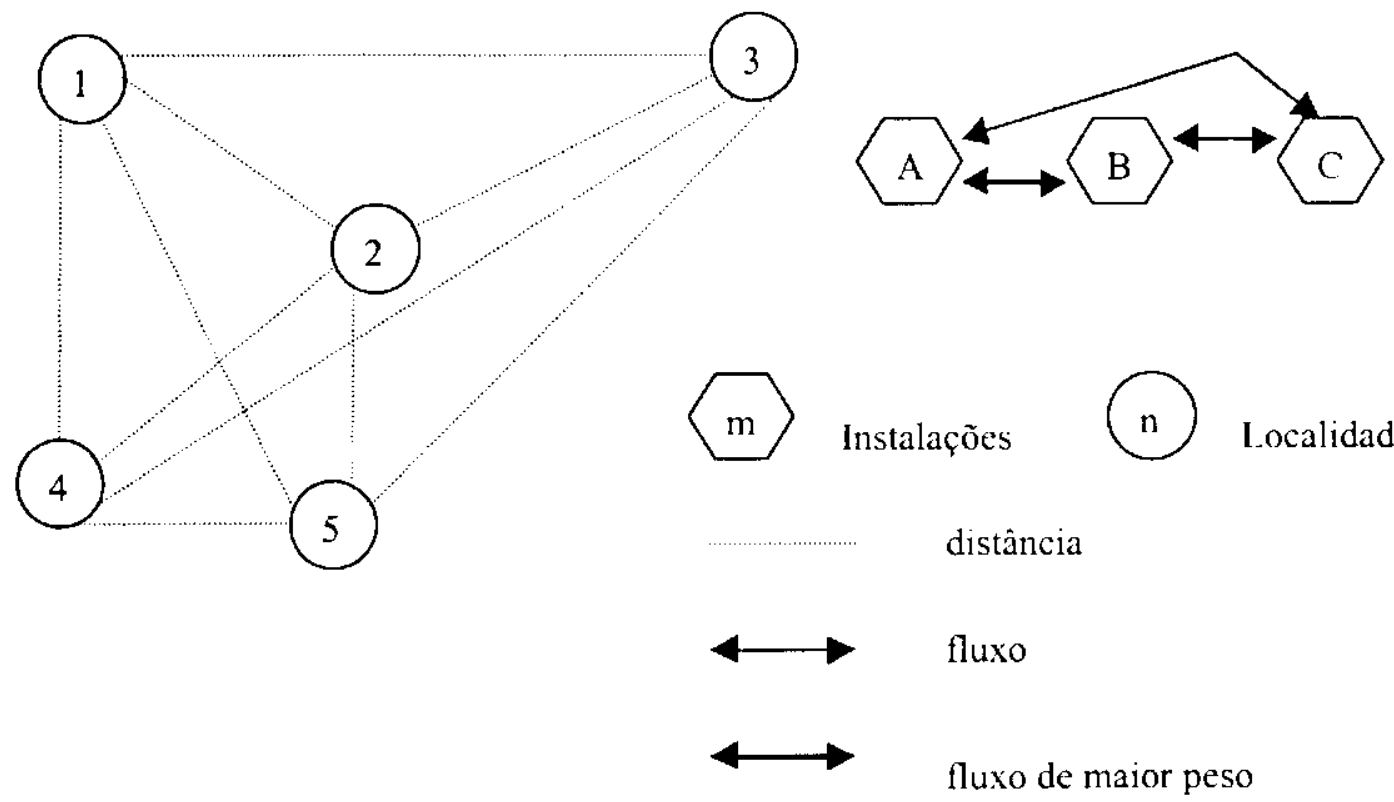

Figura 2.1. Um exemplo do QAP

Uma solução factível para o exemplo da Figura 2.1. pode ser vista na Figura 2.2.

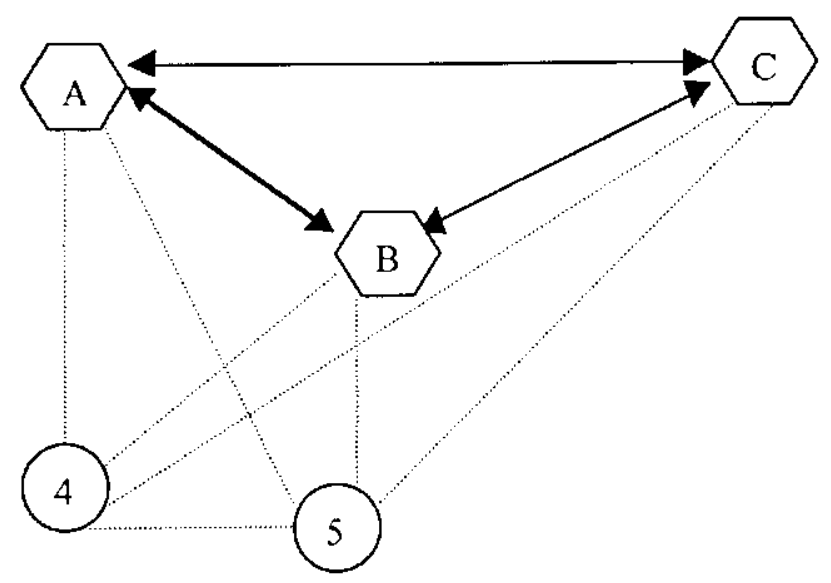

Figura 2.2. Uma solução factivel para o exemplo mostrado na Figura 2.1

Note que o fato das instalações A, B e C terem sido posicionadas nas localidades 1, 2 e 3 , respectivamente, é apenas uma coincidência. Uma outra solução factível seria aquela onde manteríamos as instalações A e C nas mesmas localidades, e posicionariamos a instalação $\mathrm{B}$ na localidade 5, como representado na Figura 2.3. 


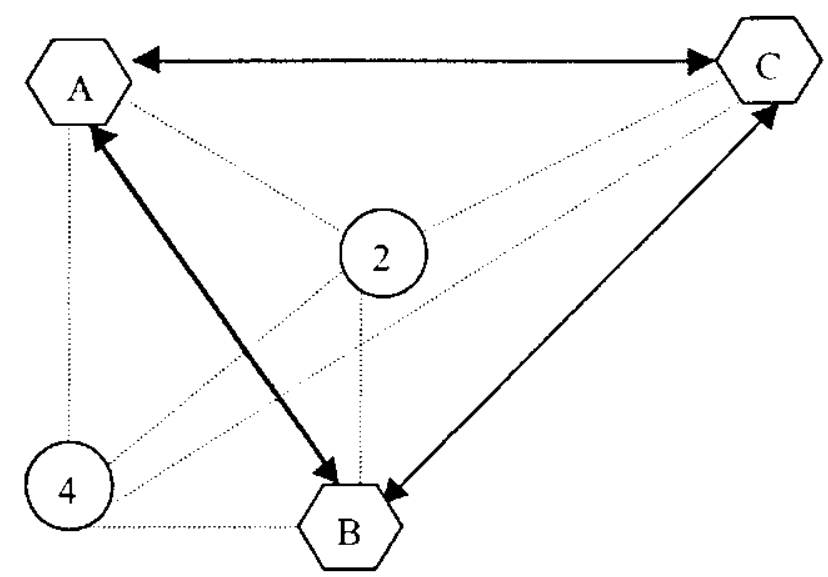

Figura 2.3. Outra solução factivel para o exemplo mostrado na Figura 2.1.

A solução mostrada na Figura 2.3. terá um valor maior para a função objetivo, já que a localidade 5 apresenta custos maiores do que aqueles referentes à localidade 2, em relação às outras duas. Essa segunda solução seria então pior que a primeira.

\subsection{Resolução do QAP}

Como uito anteı ıormcnte, o QAP pertence à classe NP-dificil. Para que se tenha uma idéia, algoritmos exatos conseguem solucionar exemplos do QAP com desempenho razoável, apenas quando esses exemplos apresentam matrizes de fluxos e distâncias de ordem máxima igual a 25 segundo Burkard e Çela, 1997, ou ainda 30, segundo Merz e Freisleben, 1999.

Por outro lado, na área de pesquisa de métodos heurísticos para problemas de Otimização, têm crescido o desenvolvimento e a aplicação das chamadas meta-heurísticas. Meta-heurísticas (Reeves, 1993 e Diaz et al., 1996) são métodos que têm como objetivo guiar procedimentos de busca heurísticos, tentando explorar de modo mais eficiente o espaço de soluções.

Devido à complexidade de resolução do QAP, os trabalhos que abordam sua resolução envolvem métodos heurísticos incorporando meta-heurísticas. Alguns exemplos de metaheurísticas utilizadas para resolução do QAP são: "Simulated Annealing" (Wilhelm e Ward, 1987), Busca Tabu (Shorin-Kapov, 1994, Taillard, 1991), Grasp (Li, Pardalos e Resende, 1994), Algoritmos Genéticos (Tate e Smith, 1995) e Algoritmos Meméticos (Merz e Freisleben, 1997, 1999, 2000). Outras referências a métodos que incorporam meta-heurísticas podem ser encontradas em (Merz e Frcisleben, 1997, 1999, 2000). 
No próximo capítulo descrevemos as características mais importantes das metaheurísticas utilizadas nesse trabalho. 
3. META-HEURÍSTICAS 


\subsection{Introdução}

Nesse capitulo são definidos problemas de Otimização, Ótimos Locais e Globais, Algoritmos Heurísticos e Meta-heurísticas. Além disso, são descritas em maiores detalhes as meta-heurísticas utilizadas nesse trabalho.

\subsection{Problemas de Otimização}

Segundo Beasley (Reeves, 1993), muitos pesquisadores estudaram nas últimas décadas a questão de se encontrar soluções ótimas para problemas que pudessem ser modelados por uma função de variáveis de decisão e, em grande parte dos casos, fossem sujeitos a restrições. Esses problemas são chamados problemas de Otimização e geralmente são modelados como a seguir:

Minimizar $f(x)$

Sujeito $a: g_{i}(x) \geq b_{i} \quad i=1, \ldots, m ;$

$$
h_{j}(x)=c_{j} \quad j=1, \ldots, n
$$

Nessa formulação geral, $x$ é uma variável de decisão e $f(),. g_{i}($.$) e h_{j}($.$) são funções$ gcrais. Ainda, deve-se notar que a formulação supõe uma minimização da função e que para a configuração de maximização as alterações são naturais.

Há uma série de classes especificas de problemas de Otimização e o que as define são as restriçôes (lineares ou não), a função objetivo considerada (linear ou não) e os valores que as variáveis de decisão (contínuas ou discretas) podem assumir.

Uma classe importante dentre os problemas de Otimização é formada pelos problemas de Otimização Combinatória, caracterizados por apresentar um número finito porém imensamente grande de soluções factiveis.

Definidos os problemas de Otimização Combinatória, é importante definir os conceitos de Ótimos Locais e Globais. 


\section{3. Ótimos Locais e Globais}

Uma característica comum em problemas de Otimização é a existência de soluçòes factíveis chamadas ótimos locais. Como o objetivo final de um mćtodo de resoluçào desse tipo de problema é a obtençào de uma solução ótima global, a existência de ótimos locais deve ser considerada e algoritmos que não os evitam podem ser tidos como ruins ou incompletos. Algoritmos eficazes devem apresentar maneiras de se desvencilhar dos ótimos locais e procurar soluções boas em novas regiões do espaço de soluções, onde possa haver soluções factiveis que melhorem o valor da função objetivo. Um conceito importante neste contexto é o de Vizinhança.

De acordo com a literatura pesquisada, uma vizinhança $\mathrm{N}(\mathrm{x}, \mathrm{A})$ de uma solução $\mathrm{x}$ ć um conjunto de soluções que pode ser alcançado a partir de $x$, através de uma operação simples A. Essa operação A pode ser tanto a inclusão, quanto a remoção de um "objeto" da solução x, por exemplo. Outra forma de alterar uma solução x é a troca de dois "objetos" já pertencentes à mesma. Essas operações são normalmente chamadas de Movimentos, principalmente numa das meta-heurísticas a ser tratada à frente. denominada Busca Tabu. Ainda, se uma solução factivel y é melhor que qualquer outra na vizinhança $\mathrm{N}(\mathrm{y}, \mathrm{A})$, então y é um ótimo local $\mathrm{cm}$ relação a essa vizinhança.

\subsection{Heuristicas}

O termo Heurística vem do grego heuriskein e significa originalmente encontrar ou descobrir. É muito importante diferenciar o significado de Hcurística em estudos relacionados à Inteligência Artificial daquele que deve ser dado nesse texto sobre Pesquisa Operacional. Em Inteligência Artificial, uma heurística é notadamente um método usado para que se encontre um ótimo global, como por exemplo um método branch-and-bound. Segundo Beasley (Reeves, 1993), essa definição é bastante razoável, mas em Pesquisa Operacional, quando se trata de uma heurística, está sendo citado um método de busca, o qual não garante que se encontre resultado algum.

Dessa forma, no contexto comum de Otimização, o termo heurística é usado como contraste a métodos que garantam uma solução global ótima. 
Ainda segundo Beasley (Reeves, 1993), uma heuristica é uma técnica que busca soluções boas (próximas à ótima) a um custo computacional razoável, não sendo capaz de garantir factibilidade ou otimalidade, ou mesmo, em muitos casos, de localizar o quào próxima uma solução factivel particular está do ótimo global.

Uma estratégia possível para solucionar um determinado prot lema de Otimização é listar todas as soluções factíveis do mesmo, avaliar as respectivas imagens da função objetivo e tomar a melhor. Todavia, ć fácil perceber que essa estratégia, denominada enumeração completa ou explícita, é ineficaz. Apesar de a princípio qualquer problema de Otimização poder ser resolvido assim, na prática isso não é verdadeiro, pois qualquer problema de tamanho razoável apresenta uma quantidade enorme de soluções factíveis.

Diante disso e da complexidade de certos problemas, para os quais o uso de algoritmos exatos é ineficiente, há a possibilidade de se usar algoritmos heuristicos, capazes de encontrar boas soluções e até mesmo ótimas, inclusive para os problemas de complexidade alta.

Segundo Diaz et al., 1996, o uso de algoritmos heurísticos como busca da solução de problemas de Otimização pode e deve ocorrer num número considerável de situaçōes, o que pode ser visto nos casos a seguir:

Caso 1: Quando não há ou não é conhecido um método exato de solução, ou este requer um gasto muito grande de tempo e ou memória. Nessa situação é preferivel a obtenção de uma solução considerada boa, de alguma maneira, do que não se ter solução alguma.

Caso 2: Quando para a aplicação em questão não se fizer necessária a otimalidade da solução. Esta é a situação na qual os valores obtidos para a função objetivo são rclativamente pequenos, sempre. Então, supõe-se que a busca pcla solução ótima do problema, que acarretará custos de tempo e memória extras, não seja uma boa alternativa se comparada ao resultado similar de uma busca mais simples que gere uma solução suficientemente boa. Em muitas aplicações, a simples melhora da solução existente é suficiente para os requisitos propostos.

Caso 3: Quando os dados que se possui não são confiáveis ou representativos, ou quando o modelo usado é uma simplificação da realidade, buscar uma solução ótima não é uma boa estratégia, pois para isso, seria necessário um processamento maior e, devido à situação, a solução ótima seria tão aproximada quanto uma solução boa qualquer. 
Caso 4: Quando há limitaçōes de tempo, espaço para armazenamento dos dados e outras. Essas limitações exigem então o uso de técnicas eficientes ou que dispensem uma maior precisão.

Caso 5: Como passo interno a outro algoritmo. Às vezes parte-se de soluções heurísticas empregando-se métodos exatos para a continuação. Naturalmente, ustando a solução inicial próxima ao valor ótimo, o algoritmo exato poderá funcionar bem em nuitas situaçòes.

\subsubsection{As classes de problemas P e NP}

Podemos dizer que um problema pertence à classe $\mathrm{P}$ (polinomial), se um algoritmo para sua resolução necessita de um tempo polinomial de execução $O(p(n))$, onde $p(n)$ é uma função polinomial e $n$ é uma medida para o tamanho do input do problema. Por outro lado, se diz pertencer à classe NP (não determinístico polinomial), se existe um algoritmo de tempo polinomial que confirme se determinada resposta para o problema é uma resposta válida ou não. Um dos problemas que pertencem à classe NP é o Problema do Caixeiro Viajante. Tal problema pode ser definido como: dados um conjunto finito de ponlus (cidades) $\mathrm{V}$ e os custus (distâncias) $\mathrm{Cij}$ entre cada par de pontos i j pertencente a $\mathrm{V}$, determinar o menor caminho que passe exatamente uma vez por cada ponto de $\mathrm{V}$.

Dentre os problemas que são ditos pertencentes à classe NP, destaca-se um grupo chamado NP-Completo. Nesse caso é equivalente dizer que se for encontrado um algoritmo de resolução em tempo polinomial para qualquer problema pertencente a essa classe, então existirá um algoritmo polinomial para a resolução de todos os problemas pertencentes à mesma. Exemplos de problema NP-Completo são o Problema do Caixeiro Viajante e o próprio QAP, um dos objetos dessa dissertação.

Desde que muitos problemas clássicos, tais como o do Caixeiro Viajante e os de Programação Inteira em geral, pertencem a essa classe (NP-Completo), encontrar um algoritmo de tempo polinomial é muito improvável, e isso implica que na resolução desses problemas deve-se investir no desenvolvimento de algoritmos de aproximação e metaheurísticas. 


\subsubsection{Tipos de Heuristicas}

São cinco os tipos de algoritmos heurísticos segundo Diaz et al., 1996, e, ainda segundo os autores, há sempre a possibilidade de mesclá-los. Deve-se dizer também que a classificação é quanto à maneira que buscam soluções e as constrócm:

Tipo 1 - Métodos construtivos: são os algoritmos heurísticos que, a cada passo, acrescentam um novo item à solução atual e verificam a factibilidade da mesma. O chamado Algoritmo Guloso é o exemplo mais famoso do tipo 1, e a lógica deste algoritmo consiste em buscar o maior beneficio a cada movimento.

Tipo 2 - Métodos de decomposição: aqui, divide-se o problema em subproblemas fazendo-se com que a saída de um seja a entrada do scguinte. Ao final, tendo sido solucionados todos os problemas menores, tem-se a solução do problema inicial (que engloba os menores). Determinados autores (Ball e Magazine, 1981) separam as definições de métodos de decomposição (onde os subproblemas são resolvidos $\mathrm{cm}$ sćric) c métodos de partição (onde os subproblemas são tratados paralelamente).

Tipo 3 - Métodos de redução: este tipo de algoritmo procura detectar característica(s) que a solução ótima certamente assumirá. Isso pode implicar, por exemplo, que uma variável de um problema de programação inteira sempre apresente o valor zero, ou que se associc o comportamento de uma variável ao de outra(s), criando entre essas variáveis uma dependência.

Tipo 4 - Métodos que manipulam o modelo original: aqui, transforma-se o modelo original a ser solucionado e busca-se a solução do novo problcma. Ao encontrá-la, tenta-se transformá-la inversamente e torná-la a soluçào realmente procurada desde o início.

Tipo 5 - Métodos de busca em vizinhança: este é seguramente o tipo que apresenta melhores resultados, em geral, e portanto o de maior apelo entre os pesquisadores. Os algoritmos desse tipo caracterizam-se por partir de uma solução factivel inicial (quc pode ser obtida através de uma outra heurística) e alterá-la iterativamente até a ocorrência de um determinado fato, definido como critério de parada do algoritmo. 


\subsection{Meta-heurísticas}

Existe a possibilidade de que um algoritmo heurístico seja guiado por outro. Essa é uma das situações em que ocorre a já citada mescla de estratégias hcurísticas. Por exemplo, pode-se imaginar um algoritmo do Tipo 5, que, a cada iteração, procure primeiro melhorar ostensivamente a solução atual, levando em conta apenas a vizinhança da mesma e, depois de ocorrida essa melhora entre num outro processo, mais claborado, que permita o percurso por outras regiões do espaço de soluções, e assim sucessivamente.

Essa segunda parte da iteração funcionaria como um guia para o processo de melhora ostensiva, pois normalmente apresenta passos refinados e amplos que agilizam o andamento da busca. Seria como um leme (segunda parte da iteração) orientando um motor (primeira parte).

Além disso, a segunda parte do algoritmo imaginado, por scr mais criativa em relação ao espaço de soluções e por guiar o processo de melhora local, normalmente recebe o nome de Meta-heurística. O prefixo meta indica superioridade ou amplidão, e é usado para determinar que csse tipo de algoritmo heurístico cumpre um papel de supervisão no processo de busca.

A seguir são descritas as meta-heurísticas utilizadas nesse trabalho, a saber, Busca Tabu, Algoritmos Genéticos e Algoritmos Meméticos.

\subsubsection{Busca Tabu}

A estratégia de Busca Tabu originou-se de conceitos segundo os quais métodos heurísticos conseguiriam boas soluções através da busca em regiões pouco visitadas ou "esquecidas", da ultrapassagem de limites de factibilidade ou otimalidade local, normalmente considerados limites de Otimização. Buscas e ultrapassagens definidas por restrições que permitem o acesso a essas regiões do espaço de soluções, às quais normalmente não se percorre em outros métodos devido às características de repetição e ou diminuição de passos e visitas que tais métodos costumam apresentar no decorrer das iterações.

A maneira com que se define o algoritmo de Busca Tabu atualmente é devida a Glover, 1997, e a Hansen, 1986. Foram ainda somadas contribuiç̃es ao passar dos anos, o que permitiu a essa estratégia bons resultados em problemas de Otimização. 
A técnica de Busca Tabu é, antes de tudo, baseada no conceito de histórico ou "memória" do algoritmo implementado. Essa proposta está relacionada ao conceito de memória e às estruturas com que será simulada essa característica. Tais estruturas de memória internas à técnica de Busca Tabu referem-se a quatro aspectos das soluções com as quais o algoritmo venha interagir: o quanto a solução é recente no histórico de execuçào (a memória do algoritmo propriamente dita, que precisa estar disponivel em forma de estrutura de dados); a frequiência dessa solução; sua qualidade e seu impacto nos testes de otimalidade. A partir dessas decisões o algoritmo então define quais soluções são tabus (o que significa não screm consideradas por um tempo determinado) e quais são aceitáveis (principalmente as pouco ou não visitadas ainda). Nào se deve confundir uma solução tabu com uma infactível.

Em Busca Tabu não se considera a idéia de evitar ótimos locais usando funçôes de probabilidade, sendo que a grande maioria dos algoritmos que seguem cssa visão de Glover, 1997, é em grande parte ou totalmente determinística. Ao invés de seguirem algum acaso na aceitação de soluções piores, implementações de Busca Tabu utilizam-se maciçamente das estruturas de memória acima citadas, cvitando visitas repetitivas a uma pequena região do espaço de soluções, buscando ultrapassar fronteiras e evitar otimalidade local, seguindo as indicações do histórico sobre vizinhanças promissoras e, deve-se enfatizar novamente, pouco visitadas. Como sempre há exceções, no ramo de Busca Tabu existem algoritmos classificados como da ordem de Buscas Tabu Probabilisticas.

No uso da memória e do histórico no processamento, algoritmos que seguem o conceito de Busca Tabu modificam a noção de vizinhança e substituem o termo $\mathrm{N}$ (solução_atual) por outro que também denota a vizinhança, mas que leva em conta o histórico: N(H, solução_atual). Assim, a estrutura histórico $(H)$ determina as soluções factiveis que podem ser atingidas por um movimento a partir da solução atual. No algoritmo, isso significa selecionar a "próxima_solução" da vizinhança $\mathrm{N}(\mathrm{H}$, solução_atual). Deve ficar claro que essa nova formulação de vizinhança é um subconjunto da anterior, e que através dos recursos de memória inerentes à Busca Tabu é que se define quais soluções factíveis vão sendo excluídas ou incluídas no novo arranjo com histórico. É o histórico que define quais soluções são atualmente tabus e quais não são. É o ponto mais decisivo da estratégia de Busca Tabu em termos de implementação ou de estruturas de dados. 


\section{- Memória de curto prazo}

Na teoria sobre Busca Tabu é muito importante diferenciar os termos memória de curto prazo e memónia de longo prazo. Cada uma dessas classificações refere-se a uma forma de se considerar a estrutura de memória dos algoritmos de Busca Tabu.

A chamada memória de curto prazo está sempre relacionada aos atributos de soluções modificados recentemente. Esses atributos cuja modificação é considerada próxima segundo um certo critério, são denominados tabu-ativos e as soluções que os contêm (ou contêm parte da estrutura dos mesmos) são então classificadas como tabus. Essas denominações e classificações ocorrem em nível de implementação normalmente, através de atributos especiais no caso das soluções-tabu e sub-atributos no caso daqueles atributos tabu-ativos. Dessa forma, é possível "eliminar" por um tempo determinado essas soluçōes-tabu do conjunto vizinhança N(solução), o que representa o foco principal da estratégia de Busca Tabu. Costuma-se atribuir ainda, certas penalidades temporárias de otimizaçào entre as soluções-tabu, resultando assim numa gradação entre essas soluções que não serão visitadas.

\section{- Memória de longo prazo}

Para muitas aplicações, o uso de Busca Tabu com memória de curto prazo mostra-se efetivo para a obtenção de soluções comprovadamente boas. Ainda assim, pode-se melhorar bastante o rendimento da meta-heurística utilizando estruturas de memória de longo prazo, que não se limita a soluções visitadas tão recentemente. Quando se trata de memória de longo prazo, ainda cstá se fazendo referência a um novo conjunto de estratégias associadas.

Uma dessas estratégias é a de estabelecer uma memória auxiliar especializada na freqüência de determinados atributos em soluções, em periodos de tempo definidos. Dessa forma o algoritmo consegue dividir o espaço de soluções em regiões que apresentam um comportamento semelhante e assim refinar o processo de determinação de soluções-tabu, agora com informações mais amplas sobre as características do problema. A freqüência dos atributos pode ser verificada em termos de transição (quando o atributo muda $\mathrm{cm}$ uma solução) e de residência (quando um atributo permanece inalterado). Esses registros que vão sendo consultados pelo algoritmo vão determinando quais os próximos passos da busca.

Dentro dos conceitos relacionados a memória de longo prazo estão também as estratégias de intensificação e de diversificação. 
As estratégias de intensificação consistem no estabelecimento de mecanismos eletivos das próximas soluções a ser visitadas, de uma forma que o algoritmo passe a ser aplicado dentro das regiões que se apresentaram melhor em relação ao objetivo de otimizaçào.

As de diversificação, ao contrário, foram projetadas para a busca em regiōes novas, o que significa geralmente a inclusão de atributos pouco comuns durante a cxecução.

Deve ficar claro que nos dois casos o conceito inicial de Busca Tabu não é perdido, ou seja, tanto num tipo de estratégia quanto no outro se escolhe conjuntos de soluções para serem considerados tabu no decorrer do processamento. A diferença entre uma cstratégia e outra está no ponto de partida: uma região muito visitada (busca tabu numa região "tabu") ou uma região nova (busca tabu simples, na verdade).

\section{- Critério de aspiração}

Em certo momento de uma Busca Tabu, é valioso que movimentos considerados tabu sejam analisados segundo algum critério interessante em relação ao problema a ser resolvido e, caso esse critéric seja atendido, a condição de tabu desses movimentos aspirc. O critério de aspiração mais natural é permitir que um movimento tabu seja realizado antes que a restrição determinada acabe, caso esse movimento resulte numa solução melhor que a melhor encontrada até então.

\section{- Um Pseudo-Código de Busca Tabu}

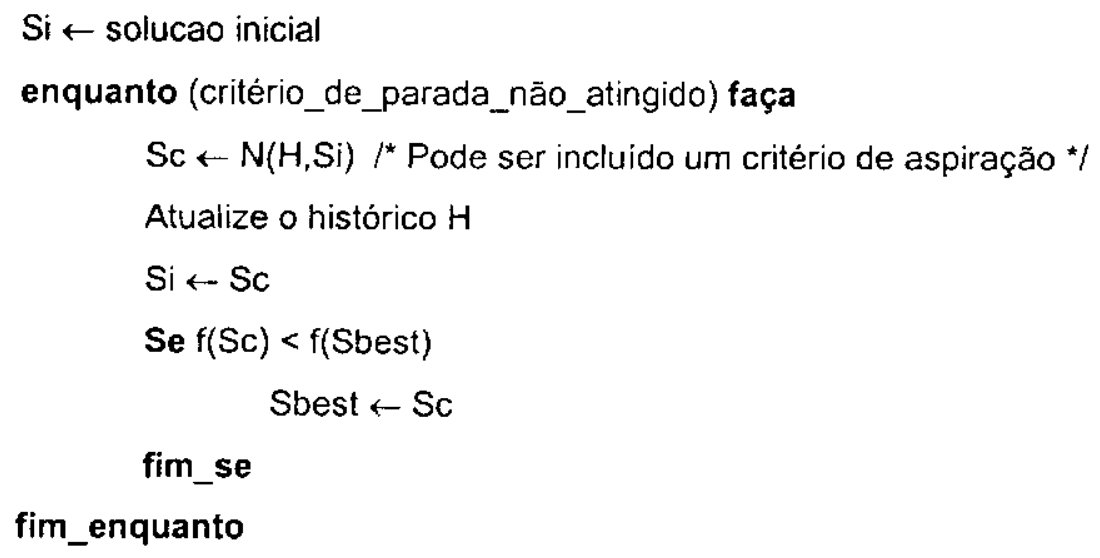

Busca Tabu pode ser inda aplicada em conjunto com outros métodos, como por exemplo dentro dos Algoritmos Genéticos que serão apresentados a seguir. 


\subsubsection{Algoritmos Genéticos}

De certa forma, afirmar que o estudo sobre Algoritmos Genéticos seja exclusivamente contemporâneo não seria inteiramente verdade, pois a origem dessa pesquisa data de quasc quarenta anos. Esse início, entretanto, deu-se no ramo de Inteligência Artificial, sendo que experiências de maior vulto na área de Otimização e Pesquisa Operacional só surgiram ultimamente.

Um Algoritmo Genético, no contexto de Otimização e Pesquisa Operacional, pode ser descrito como uma estratégia de direcionamento aplicada numa busca aleatória. A principal introdução a Algoritmos Genéticos foi realizada por Holland na Universidade de Michigan nos anos sessenta e setenta, c o primeiro tratamento sistemático e fortemente teórico dado a essa técnica foi publicado em seu livro Adaptation in Natural and Artificial Systems, publicado em 1975 (Holland, 1975). Também Goldberg, 1989, contribuiu com intcressantes adendos, notadamente de preocupação mais prática, nos anos que se seguiram.

A denominação Algoritmo Genético deriva da analogia entre a representação de uma estrutura complexa através de vetores de dados, com a noção proveniente da Biologia sobre a estrutura genética de um cromossomo. No processo de evolução das espécies, por exemplo de plantas e animais, a descendência manifesta características herdadas, características essas determinadas em nivel genético devido à combinação do material presente nos cromossomos dos pais. Pode-se assim observar como um processo parecido a busca por soluções boas para problemas dificeis, através da combinação de soluções já conhecidas. A analogia certamente não é perfeita, uma vez que nem mesmo o processo real de mistura cromossômica é inteiramente descrito e coberto $\mathrm{cm}$ todos os detalhes pelos especialistas, mas foi suficientemente atrativa para que muitas pesquisas em Otimização seguissem nesse rumo.

$\mathrm{Na}$ maioria das aplicações, os vetores de dados ou cromossomos são estruturas que se compõem simplesmente de zeros e uns formando strings.

No uso de Algoritmos Genéticos, ao contrário das outras meta-heurísticas apresentadas anteriormente, uma série de soluções é utilizada a cada iteração, a qual denomina-se População, de onde (ou dentre os seus descendentes, o que é mais provável) será escolhida a melhor solução.

Segundo Reeves, 1993, uma outra c racterística importante dos Algoritmos Genéticos é a de não necessariamente manipularem informações específicas a respeito do problema 
tratado, no decorrer do processo evolutivo dos cromossomos. Em outras palavras, a partir da representação de uma solução em um cromossomo, a melhoria dessa solução é um problema diferente e independente do problema original.

Na teoria sobre Algoritmos Genéticos, Operadores Genéticos são processos caracterizados por realizarem a manipulação da População atual, visando alguma alteraçào ou avaliação da mesma. Alguns dos Operadores Genéticos clássicos para a manipulação de uma população de cromossomos são: Operador de Cruzamento (que realiza o cruzamento das soluções - ou cromossomos) e Operador de Mutação (um processo alcatório de alteração de uma solução - ou cromossomo).

Continuando a analogia com a Genćtica, en Algoritmos Genéticos, variáveis são relacionadas a genes, os possiveis valores assumidos por uma variável relacionados a alelos e a posição de uma variável numa string é chamada locus (em situações simples, o locus de uma variável ou gene não é importante, ainda que em casos mais complexos seja). Ainda, em Genética a estrutura real dos cromossomos é denominada Genótipo e a aparência física baseada na mesma é dita Fenótipo. Em Otimização, quando citados no ramo de Algoritmos renéticos, o Genótipo é a codifiraŗi o das estruturas que é processada através do algoritmo, enquanto o Fenótipo é o conjunto de parâmetros compilado ou interpretado.

Enfim, quando da avaliação de uma população de cromossomos, a qualidade dos mesmos dentro do contexto de Pesquisa Operacional é dita fitness ou função de aptidão.

Na busca pela solução ótima de problemas de Otimização, um Algoritmo Genético, de forma geral, funciona da seguinte maneira: inicia-se com uma certa população $\mathrm{P}$ de cromossomos (sempre representando soluções) dos quais a função de aptidão é conhecida. A função de aptidão de cada cromossomo é, normalmente, o valor gerado pela função objetivo para a respectiva solução avaliada, ainda que outras formas de avaliação existam e possam ser empregadas com sucesso, às vezes até maior. Então é feita a escolha de dois ou mais pais segundo alguma regra, e é aplicado a esses um operador de cruzamento (mais à frente são descritos alguns tipos de operador de cruzamento).

A partir da execução do operador de cruzamento, os descendentes são incluídos na população. Nesse momento pode-se também escolher cromossomos para serem retirados da população segundo algum critério (normalmente relacionado à função de aptidão). Na seqüência, o processo é repetido a cada geração (ou iteração), sendo que as regras para escolha de pais podem ser alteradas, assim como pode ser alterado o esquema de eliminação das 
soluções a sair da População. Dessa forma, una população deixa de existir totalmente ou em parte (isso dependendo do número de cruzamentos de cromossomos comparado com o tamanho da população), e uma nova população passa a ser tratada. A tendência é que esta nova população seja melhor que as anteriores, pois se trata de um modelo evolucionário baseado na idéia de sobre ivência do indivíduo mais forte. Ainda, também com alguma probabilidade de ocorrência, pode ser aplicado un operador de mutação em membros da população, visando a uma maior diversidade do conjunto. Um exemplo de operador de mutação pode ser a alteração de alelos do cromossomo segundo uma certa probabilidade, como mostra a Figura 3.1.

$$
\text { Cromossomo1 } \quad 0 \underline{0} 00101
$$

Cromossomo1 mutante 0100101

Figura 3.1. Exemplo de um operador de mutação

\section{- Alguns Tipos de Operador de Cruzamento}

\section{Operador to Cruzamento em 'im ponts}

Nesse tipo de operador de cruzamento, cada pai tem seus genes separados em um único ponto e então uma das metades de cada é trocada pela respectiva metade do outro. Sejam os pais P1 e P2, segue a geração dos descendentes D1 e D2 como mostra a Figura 3.2.

$\begin{array}{llll}\text { P1 } & 1010010 & \text { D1 } & 101 \underline{1001} \\ \text { P2 } & \mathbf{0 1 1 1 0 0 1} & \text { D2 } & \underline{0110010}\end{array}$

Figura 3.2. Exemplo do Operador de cruzamento em um ponto

\section{Operador de Cruzamento em vários pontos}

Semelhante ao anterior, mas com um aumento no número de divisões dos cromossomos escolhidos para cruzamento, separando-os por mais de um ponto, como mostra a Figura 3.3. Uma recombinação desse tipo traz à população uma maior quantidade de candidatos a novos membros.

$\begin{array}{llll}\text { P1 } & 1010010 & \text { D1 } & 101 \underline{1010} \\ \text { P2 } & \underline{0111001} & \text { D2 } & \underline{01100 \underline{1}}\end{array}$

Figura 3.3. Operador de cruzamento em vários pontos 


\section{Operador de Cruzamento uniforme}

Esse operador nāo utiliza pontos de cruzamento, mas determina, através de um parâmetro global, qual a probabilidade de cada alelo ser herdado de qual pai.

\section{Operadores de Cruzamento Especificos ao QAP}

Devido à sua complexidade, determinados problemas geram trabalhos que buscam desenvolver operadores de cruzamento específicos. Para o Problema do Caixeiro Viajante, por exemplo, há uma série de operadores de cruzamento específicos tais como: Cruzamento baseado em ordem, Cruzamento baseado em posição, Cruzamento preservativo máximo c Cruzamento de alteração de margem, entre outros, apresentados em Larrañaga et al., 1999.

Isso também ocorre na pesquisa sobre o QAP. A seguir sào descritos dois operadores de cruzamento específicos para o QAP.

O operador de cruzamento DPX (distance preserving crossover), proposto para o QAP por Merz e Freisleben, 1999, é baseado no conceito de distância entre as soluções, ou scja, no número de alelos diferentes entre duas soluções. Este tipo de cruzamento mostrou-se eficaz também para o Problema do Caixeiro Viajante, como mostrado em Freisleben e Merz, 1996a, e Freisleben e Merz, 1996b. Inicialmente, todos os posicionamentos coincidentes entre os dois pais são repetidos no descendente. Então as localidades restantes no descendente são preenchidas aleatoriamente, porém desde que seja mantida entre o descendente e cada pai a mesma distância que ocorrer entre os dois pais.

Outro operador é o chamado $\mathrm{CX}$, assim chamado por ter sido proposto para a resolução do Problema do Caixeiro Viajante com o nome Cycle Crossover (Oliver et al., 1987). Esse operador se mostrou mais eficaz para o QAP, quando comparado ao DPX, segundo Freisleben e Merz, 2000. Dessa forma foi o operador escolhido para ser implementado nesse trabalho. No capítulo onde são descritas as meta-heurísticas implementadas, esse operador é descrito detalhadamente. 


\section{- Um Pseudo-Código de um Algoritmo Genético}

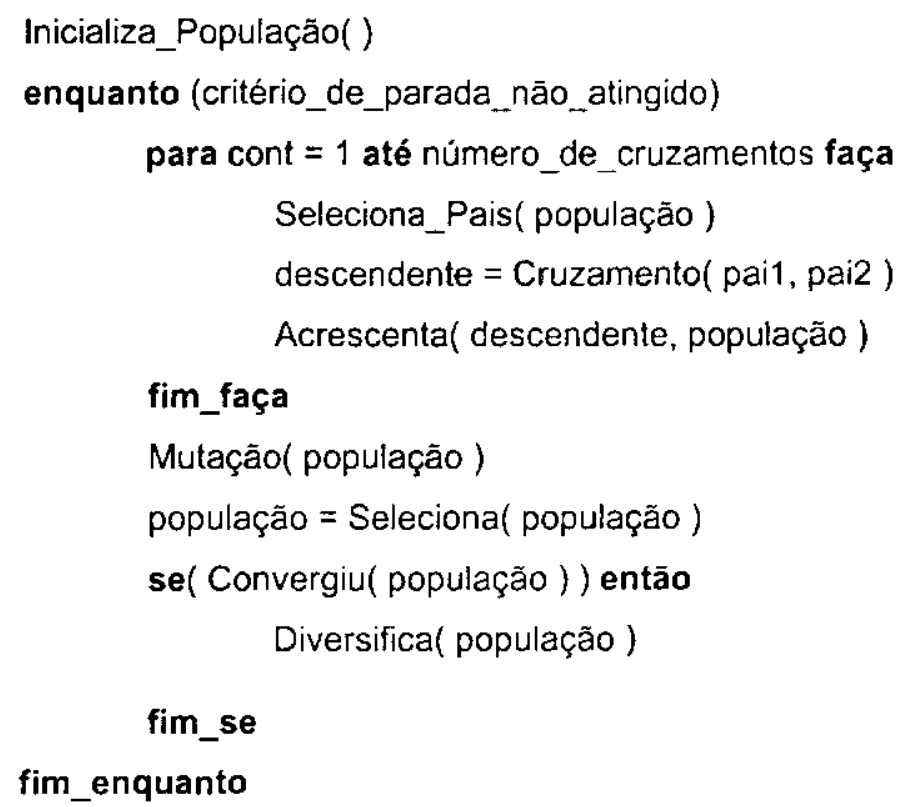

De acordo com Diaz et al., 1996, os Algoritmos Genéticos em aplicaçào pura têm apresentado resultados animadores, inclusive para problemas complexos em áreas de estudo como Pesquisa Operacional, Planejariı sto Paralelo, Eletrônica, Bioicsia Molecular e Físicoquímica, Engenharia Civil, Bancos de Dados, Geofísica e Inteligência Artificial, devido ao constante acesso do método a um grande subconjunto do espaço total de soluções, a cada iteração.

Essa possibilidade de processar mecanismos de otimização em várias soluções ao invés de uma, é a grande diferença entre os Algoritmos Genéticos e as demais metaheurísticas não baseadas em evolução. Verifica-se então a partir disso que interações entre heurísticas podem vir a calhar também junto a esse tipo de busca. É aí que aparece a noção de Algoritmo Memético, na qual as definições básicas sobre os genéticos permanecem, porém com a adição de buscas locais ostensivas a cada iteração.

\subsubsection{Algoritmos Meméticos}

Os Algoritmos Meméticos (AMs), denominação proposta por Moscato em 1989, são métodos meta-heurísticos de busca baseados em populações. Nesse aspecto, eles têm certa similaridade com os chamados Algoritmos Genéticos e as Estratégias de Evolução. Basicamente, os AMs utilizam uma população de "agentes", que possuem informação sobre os métodos de resolução particulares ao dominio do problema considerado. Os AMs então 
combinam periodos de busca individual desses agentes com algoritmos que trocam informação entre as soluções, em muitos casos utilizando operadores de cruzamento de soluções anteriores encontradas pelos agentes. Por esta razào, muitos pesquisadores os chamam de Algoritmos Genéticos Hibridos (AGHs). Nào obstante, existem algumas implementações de AMs que não têm nenhuma analogia com a Evoluçào Biológica, logo, é dito que em geral os $\mathrm{AGHs}$ estão incluidos nos $\mathrm{AMs}$ mas a recíproca não é verdadeira. Pelo fato de serem facilmente implementáveis em sistemas de computação paralelos, também são chamados de Algoritmos Genéticos Paralelos, mas essa denominaçào é ainda mais confusa, pois não se consegue diferenciá-los daqueles algoritmos que têm fortes analogias com a Evolução Biológica, e não usam informação do problema para fazer períodos de busca individual.

Os AMs têm se mostrado muito eficazes em vários problemas de otimização combinatória, como pode ser visto nas várias publicações encontradas na página da Internet a eles dedicada (MAs Home Page, 2002), ou ainda em (Moscato, 1999) e (Moscato c Cotta, 2001).

Segundo Moscato, 1989, os AMs podem ser vistos como uma estratégia onde os elementos da população, preferencialmente chamados de "agentes" e não "indivíduos", passam não só a se reproduzir mas a competir e a cooperar entre si. No AM proposto por Moscato e Norman, 1989, para o problema do Caixeiro Viajante, foi implementado um critério de "vizinhança" entre os agentes. A competição se dá então entre os agentes consecutivos num anel e a cooperação entre os mais afastados. O processo de cooperação é definido pela cessão de características de um agente para a formação de um novo, enquanto que a competição constitui-se da eliminação de um agente por outro, normalmente em uma decisão baseada em funçōes de probabilidade, que por sua vez envolvem a função de aptidão aplicada aos agentes envolvidos ou envolvem diretamente a função objetivo do problema de otimização considerado.

O termo "Memético" é derivado de "meme", que pode ser entendido como o termo análogo a gene, no contexto de Evolução Cultural. Em um Algoritmo Memético normalmente é levado em conta o conhecimento existente sobre o problema tratado, e assim as soluções descendentes são geradas a partir de'soluções já bem desenvolvidas com estratégias "ad-hoc" para o problema, ao contrário dos métodos evolutivos tradicionais (Moscato, 1989, 1999 e Moscato e Cotta, 2001). Como conseqüencia, cada agente pode fazer uso de soluções obtidas 
por outros métodos. Este conhecimento pode ser: características da solução ótima, heurísticas (métodos de busca local assim como meta-heurísticas diferentes), algoritmos exatos truncados etc. Além disso, diferentes agentes podem fazer uso de diferentes algoritmos, e mesmo ter diferentes comportamentos que parametrizam o operador de cruzamento (Berretta e Moscato, 1999).

Segundo Diaz et al., 1996, o êxito dos Algoritmos Meméticos está rclacionado ao equilibrio existente entre a rapidez da busca local e a ocorrência de diversidade no espaço de soluções utilizado, o que evita a convergência prematura desse método.

A seguir há o pscudo-código de um exemplo de algoritmo Memético que usa busca local no indivíduo (ou agente) gerado depois do operador de cruzamento.

\section{- Um Pseudo-Código de um Algoritmo Memético com busca local}

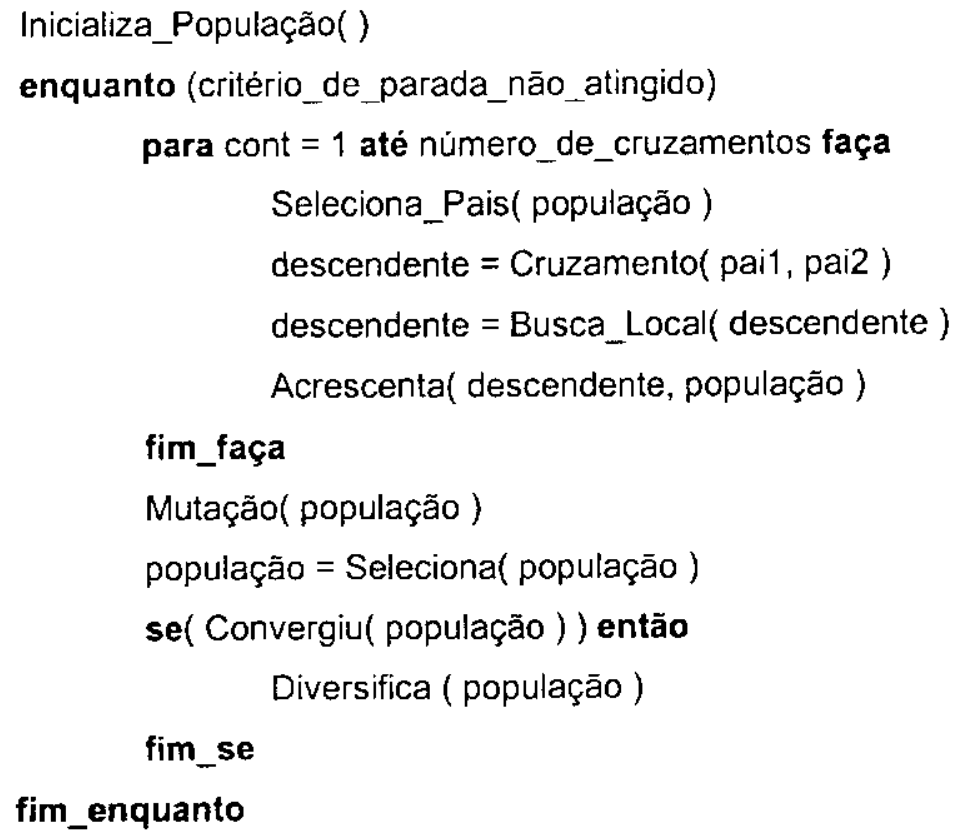


4. META-HEURISTICAS IMPLEMENTADAS 


\subsection{Introdução}

Neste capítulo são descritas as meta-heurísticas inplementadas. Os métodos utilizados foram Busca Tabu, Algoritmo Genético e Algoritmo Memético, sendo que este último foi implementado em duas versões, uma utilizando Busca Tabu e outra utilizando uma Busca Local, ambas encontradas na literatura. Além da descrição dos parâmetros usados cm cada estratégia, são apresentados os pseudocódigos e os respectivos comentários sobre estes últimos.

\subsection{Busca Tabu}

O algoritmo de Busca Tabu implementado foi desenvolvido por Taillard, 1991, e apresenta as características descritas a seguir.

\section{- Representação de uma solução}

Uma solução é representada por um vetor unidimensional de inteiros, onde cada posição representa uma localidade e cada inteiro armazenado rcpresenta uma instalação.

Na Figura 4.1., a instalação 2 está na localidade 1, a instalação 4 está na localidade 2 e assim sucessivamente.

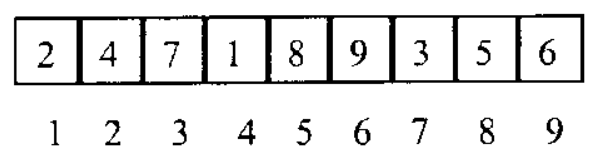

Figura 4.1. Representação por vetor de uma solução factivel para um exemplo do QAP de ordem 9.

\section{- Movimento}

Um movimento consiste na troca de instalações entre duas localidades. A Figura 4.2. apresenta um movimento, onde as localidades 3 e 8 têm suas respectivas instalações ( 7 e 5) trocadas em relação à solução representada pela Figura 4.1. 


\begin{tabular}{|l|l|l|l|l|l|l|l|l|}
\hline 2 & 4 & 5 & 1 & 8 & 9 & 3 & 7 & 6 \\
\hline 1 & 2 & 3 & 4 & 5 & 6 & 7 & 8 & 9
\end{tabular}

Figura 4.2. Movimento entre as localidades 3 e 8, em relação à solução representada pela Figura 4.1.

\section{- Atributo}

O atributo é um par $(\mathrm{i}, \mathrm{j})$ que representa duas localidades, que têm as instalações trocadas num movimento.

\section{- Critério tabu}

Quando ocorre uma troca de instalações entre um par de localidades i e j, ou seja, um movimento, cssa mesma troca fica proibida de ser desfeita durante o respectivo tempo tabu.

\section{- Tempo tabu}

A cada movimento considcrado tabu é atribuido um tempo tabu gerado aleatoriamente num intervalo $(\mathrm{a}, \mathrm{b})$, onde tais valores estão relacionados ao tamanho do excmplo sendo resolvido. No capítulo de resultados computacionais estão os valores testados.

\section{- Critério de Aspiração}

Um movimento deixa de ser tabu antes da itcração determinada, quando sua escolha diminui o valor da função objetivo, comparando-se com a melhor solução encontrada até então.

\section{- Pseudocódigo da Busca Tabu}

início

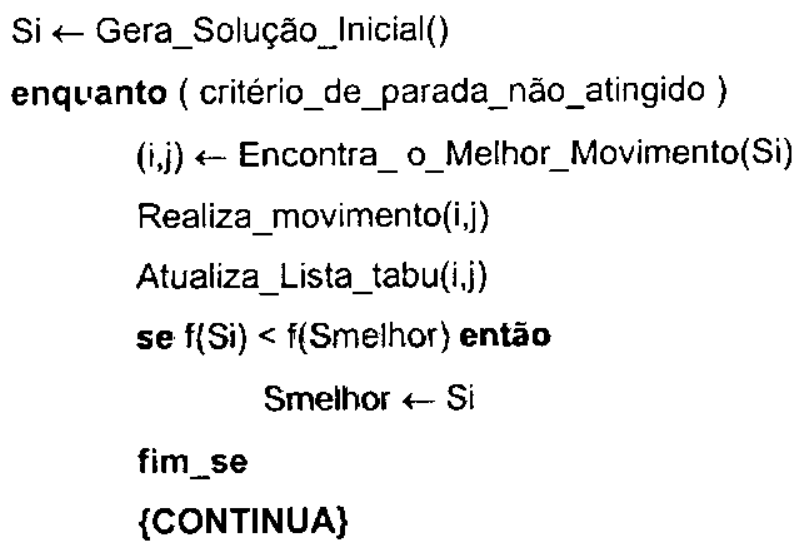




\section{Armazena_Diferença_Entre_os_Custos() \\ fim_enquanto}

fim

onde

Gera_Solução Inicial()

Gera uma solução inicial alcatoriamente.

\section{Encontra o Melhor Movimento()}

início

$\Delta$ melhorcusto $\leftarrow$ infinito

para $i=1$ até $n-1$ faça

para $j=i+1$ até $n$ faça

movimento $\leftarrow(\mathrm{i}, \mathrm{j})$

se $(\Delta c u s t o(i, j)<\Delta$ melhorcusto e (i,j) é não tabu) ou $((i, j)$ aspirou condição de tabu) então

melhor_movimento $\leftarrow(\mathrm{i}, \mathrm{j})$

$\Delta$ melhorcusto $\leftarrow$ Acusto $(i, j)$

se (aspirou condição de tabu) entāo

termina a funçāo

fim_se

fim_se

fim_para

fim_para

retorna melhor_movimento

fim

Essa função avalia todos os movimentos $(i, j)$ com $i=1, \ldots, n$ e $j=1, \ldots, n$ e escolhe o movimento não tabu que fornece uma variação na função objetivo, a melhor possível ( $\Delta$ melhorcusto). Contudo, se algum movimento tabu passa pelo critério de aspiração, o mesmo é cscolhido de antemão.

Nessa busca tabu, ou é encontrado um posicionamento que vence o melhor resultado atual, ou é escolhido o melhor movimento possivel, mesmo que este seja ruim, com o objetivo de se alcançar novas regiões do espaço de soluções. Pode ocorrer a situação raríssima em que todos os movimentos candidatos sejam tabu e nenhum atenda ao critério de aspiração, e nesse caso as iterações seguem até que um dos pares candidatos seja liberado. 


\subsection{Algoritmo Genético}

O Algoritmo Genético implementado e descrito a seguir tem as características do algoritmo descrito em Merz e Freisleben, 1999.

\section{- Representação}

Um indivíduo é representado por um vetor unidimensional de inteiros, onde cada posição representa uma localidade e cada elemento representa uma instalação, como descrito em Busca Tabu. A população é representada por un conjunto desses vetores.

\section{- Seleção dos pais}

A selcçào dos pais é sempre alcatória e resulta $\mathrm{cm}$ dois escolhidos (característica básica de um algoritmo genético que pode ser alterada).

\section{- Operador de Cruzamento $\mathrm{CX}$}

O operador de cruzamento CX foi primeiramente proposto por Oliver et al., 1987, para a resolução do Problema do Caixeiro Viajante, com o nome Cycle Crossover. A sua utilização do QAP é descrita a seguir.

Todas as instalações designadas para a mesma localidade nos dois pais são também designadas para essa localidade no descendente. Então, dentre as localidades restantes, uma é selecionada aleatoriamente e a instalação correspondente a um dos pais (selecionado também aleatoriamente) é designada para a localidade correspondente no descendente. Em seguida, a instalação não selecionada no passo anterior é designada para a localidade correspondente à localidade dessa instalação no pai já selecionado aleatoriamente. Esses passos são repetidos até que uma instalação já designada é encontrada e então se reinicia o procedimento, a partir da primeira localidade vazia encontrada no descendente.

Esse operador tem as características necessárias a um cruzamento, ou seja, garante que no descendente haja todas as $\mathrm{n}$ instalações também presentes nos pais, e que não aconteçam repetições das mesmas.

A Figura 4.3. ilusıra a aplicação deste operador em um exemplo do QAP de tamanho 9. A ilustração foi retirada de Merz e Freisleben, 1999. 
Localidades:

Pai A:

Pai B: $\begin{array}{lllllllll}1 & 2 & 3 & 4 & 5 & 6 & 7 & 8 & 9\end{array}$

\begin{tabular}{|l|l|l|l|l|l|l|l|l|}
\hline 2 & 4 & 7 & 1 & 8 & 9 & 3 & 5 & 6 \\
\hline
\end{tabular}

\begin{tabular}{|l|l|l|l|l|l|l|l|l|}
\hline 7 & 4 & 5 & 8 & 3 & 9 & 1 & 2 & 6 \\
\hline
\end{tabular}

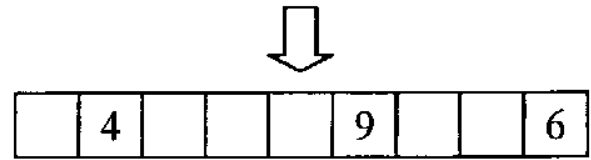

П

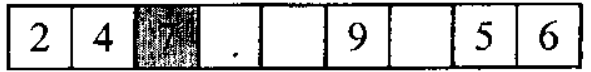

27

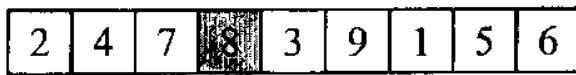

[1

Descendente:

Figura 4.3. Exemplo do operador de cruzamento $C X$

Primeiramente, as instalações 4, 9 e 6, que estão posicionadas na mesma localidade nos dois pais, são herdadas pelo descendente exatamente nas localidades originais.

Em seguida é escolhida uma localidade vaga aleatoriamente, por exemplo, a 3. Então é escolhida também aleatoriamente a instalação da localidade 3 de um dos pais, por exemplo a instalação 7, que é herdada pelo descendente na sua localidade original (instalação/localidade sombreadas). Escolhendo-se a instalação 7 do pai A, a instalação 5 do pai B foi impedida de ocupar a localidade 3. Então a instalação 5 é herdada pelo descendente na localidade correspondente à do pai $\mathrm{A}$, ou seja, a localidade 8. Da mesma forma, agora a instalação 2 ficou impedida de ocupar a localidade 8, e então é posicionada na localidade 1 do descendente, a mesma que ocupa no pai A. O passo seguinte seria posicionar a instalação 7 , porém esta já foi posicionada. Então se escolhe a localidade vaga mais à esquerda, que é a 4, e nesta localidade é posicionada a instalação correspondente no pai $\mathrm{B}$, a 8 , ficando invertida a opção inicial pelo pai (instalação/localidade sombreadas). Seguindo os mesmos passos iniciais, a instalação 1 é herdada pelo descendente na localidade correspondente à do pai B, ou 
seja, a localidade 7. O mesmo ocorre com a instalação 3 na localidade 5. Desta maneira, cada instalação fica posicionada numa localidade do descendente.

\section{- Operador de Mutação}

São realizadas trocas sucessivas entre pares de instalações, num número de vezes prédeterminado. A segunda instalação escolhida para troca a cada passo pertencerá ao par trocado no próximo. A distância entre o cromossomo original e o resultante da sequêencia de trocas é o número de trocas realizadas mais 1 .

A Figura 4.4. ilustra a aplicação do operador de mutação num indivíduo. A ilustração foi retirada de Merz e Freisleben, 1999.

Localidades:

I1:

Troca 9 e 4:

Troca 4 e I:

Troca 1 e 3:

I2:

$$
\begin{array}{lllllllll}
1 & 2 & 3 & 4 & 5 & 6 & 7 & 8 & 9
\end{array}
$$

\begin{tabular}{|l|l|l|l|l|l|l|l|l|}
\hline 2 & 4 & 7 & 1 & 8 & 9 & 3 & 5 & 6 \\
\hline
\end{tabular}

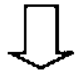

\begin{tabular}{|l|l|l|l|l|l|l|l|}
\hline 2 & 7 & 1 & 8 & $x_{1}$ & 3 & 5 & 6 \\
\hline
\end{tabular}

$\eta$
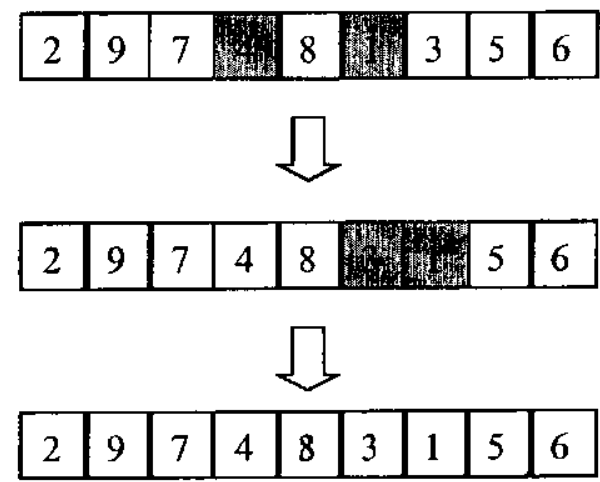

Figura 4.4. Exemplo do operador de mutaçāo

Inicialmente, as instalações 9 e 4 são trocadas de localidade. Em seguida a 4 é trocada com a 1, e a 1 é trocada com a 3 . A distância (número de alelos diferentes entre I1 e I2) é 3 (número de trocas) mais 1 . 


\section{- Função de Aptidão}

A função de aptidão de um indivíduo é o valor da função objetivo aplicada ao mesmo.

\section{- Atualização da População}

A cada geração, é selecionado um grupo de indivíduos de pior valor da função de aptidão que ultrapasse o tamanho inicial da populaçào. Esse grupo é então eliminado.

\section{- Pseudocódigo do Algoritmo Genético}

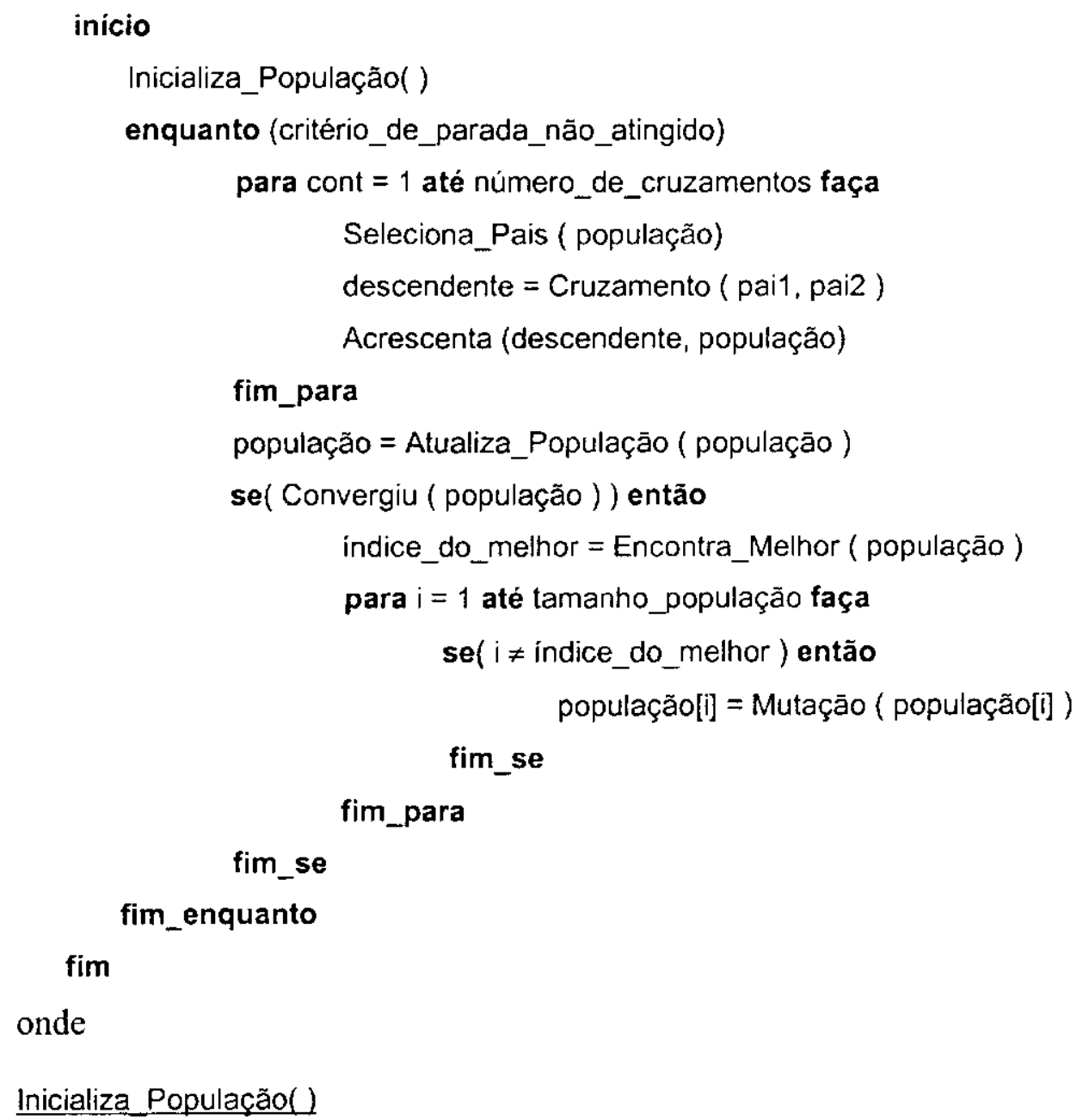

Gera aleatoriamente um número pré-determinado de indivíduos.

\section{Seleciona Pais( população)}

Seleciona dois individuos aleatoriamente. 


\section{Cruzamento(pai1, pai2)}

Recombina os dois cromossomos pais selecionados, segundo o operador $\mathrm{CX}$ descrito anteriormente.

\section{Acrescenta( descendente, população)}

Acrescenta o descendente gerado à população.

\section{Atualiza População (população)}

A quantidade de cromossomos de pior função de aptidão, que ultrapasse o tamanho inicial da população, é eliminada.

\section{Convergiu( população)}

Inicialmente verifica se a distância (número de alelos diferentes) entre os indivíduos de toda a população é pequena. Essa margem é definida por uma constante. A seguir, verifica se o melhor custo atual é pouco melhor que o armazenado há um número estipulado de iterações. Essa outra margem de comparação e o número estipulado de iterações também são definidos por uma constante. Se ambas as condiçōes forem verdadeiras, é considerado que a população convergiu.

\section{Encontra Melhor(população)}

Encontra o indivíduo com melhor valor de função de aptidão.

\section{Mutação( individuo)}

Altera o posicionamento no individuo, segundo o operador descrito antcriormente. $\mathrm{O}$ operador de mutação é aplicado sobre toda a população, com a exceção do individuo de melhor função de aptidão.

\subsection{Algoritmo Memético}

Inicialmente implementou-se o Algoritmo Memético encontrado em Merz e Freisleben, 1999, que utiliza uma busca local. A seguir, substituímos a busca local pela Busca Tabu descrita na seção 4.2. Assim, os componentes dos algoritmos já foram descritos anteriormente. A seguir o pseudocódigo: 


\section{- Pseudocódigo do Algoritmo Memético}

início

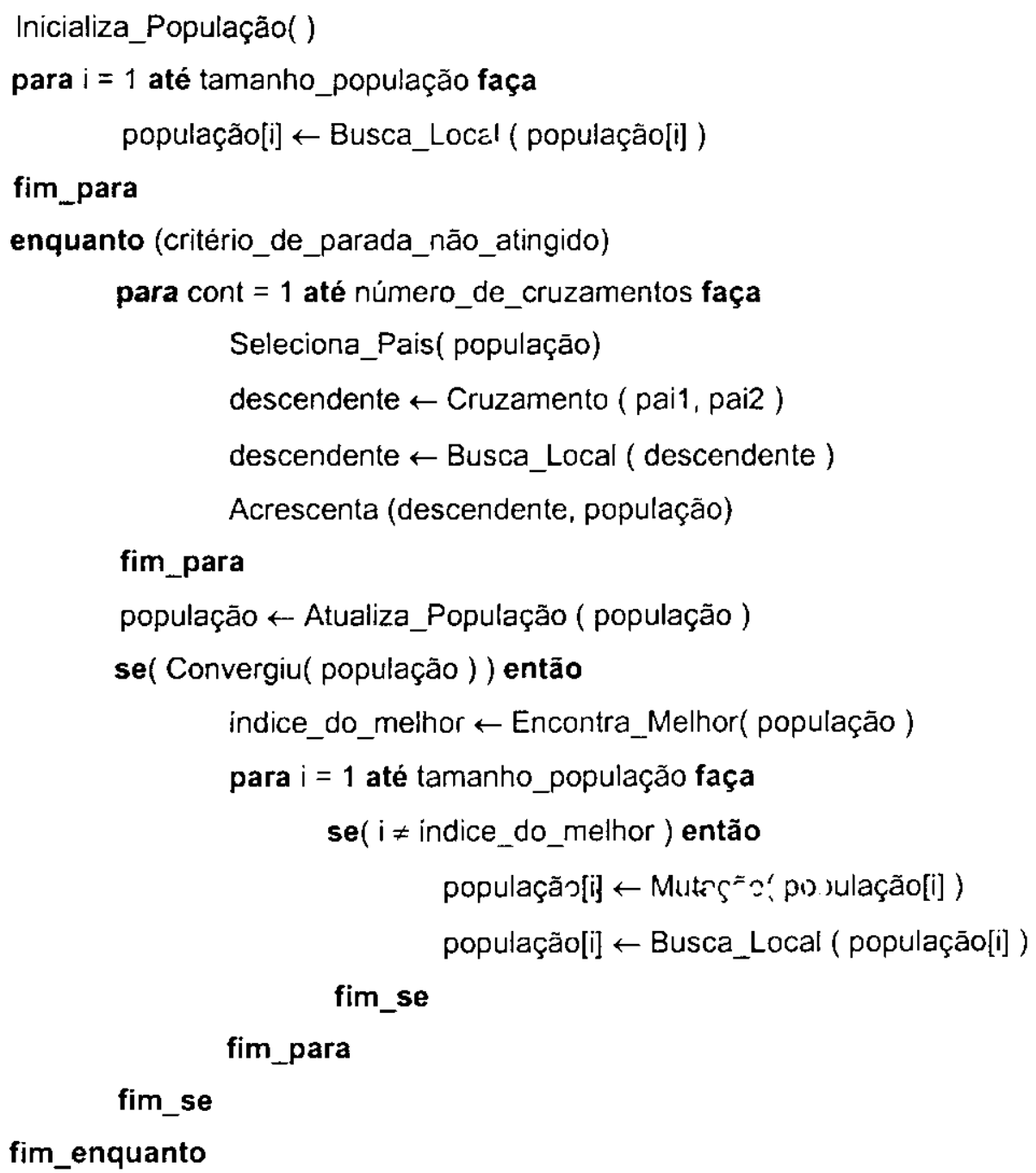

A Busca Local é usada na melhora da população inicial, dos descendentes gerados nos cruzamentos e dos descendentes resultantes das mutações. Foram implementadas duas versões de algoritmos meméticos. Na primeira, em Busca_Local() utilizou-se o algoritmo chamado Busca Local Fast-2-Opt, encontrado em Merz e Freisleben, 2000. A segunda versão de algoritmo memético utiliza a Busca Local Tabu descrita na seção 4.2. A seguir é descrita a Busca Local Fast-2-Opt.

A busca local Fast-2-Opt realiza o primeiro movimento simples (troca de duas instalações entre as respectivas localidades) que melhore o melhor custo atual. Isso significa que essa busca não avalia a qualidade dos possíveis movimentos seguintes, o que acelera seu desempenho sem grande perda na qualidade das soluções. Para que fosse acelerada ainda mais, e ainda sem perda de qualidade, usou-se a técnica "don't look bits", que consiste em 
desconsiderar a localidade i na iteração corrente caso esteja marcada por um bit proibitivo num vetor auxiliar. A localidade i é marcada no vetor auxiliar com o bit de proibição, se não fizer parte do movimento de melhora anterior. Quando um movimento de melhora é realizado, os bits auxiliares das duas localidades envolvidas são liberados.

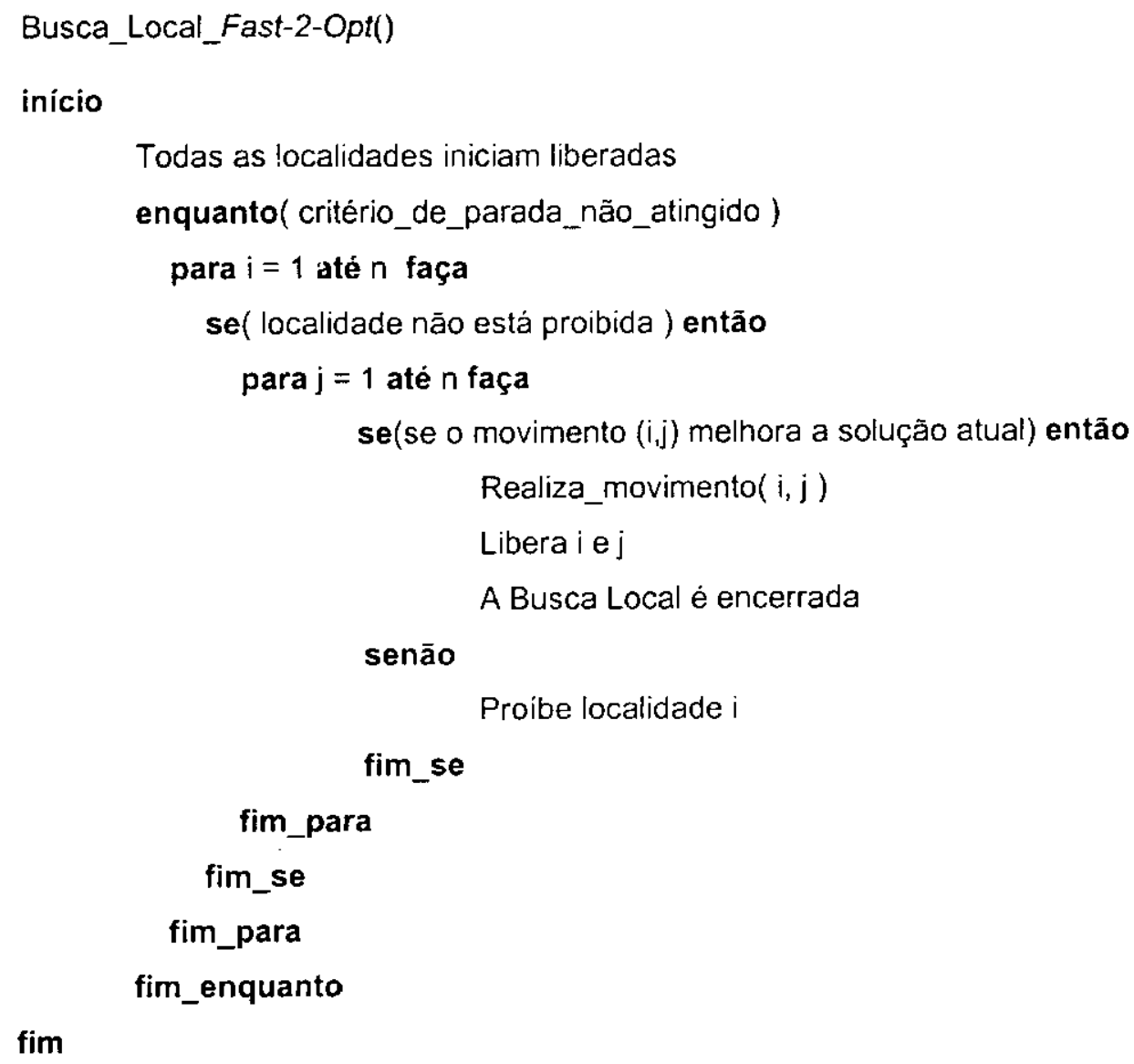

Note que se a localidade $\mathrm{i}$ valer 1 e for proibida, e numa iteração posterior o movimento $\mathrm{i}=3 \mathrm{e} \mathrm{j}=1$ for realizado, o índice 1 do vetor auxiliar (ou seja, a localidade 1) será liberado. En outras palavras, por haver um único vetor auxiliar, uma instalação escolhida libera a localidade de mesmo índice, se esta estiver proibida.

No capítulo seguinte estão descritos os testes e resultados computacionais obtidos. 
5. RESULTADOS COMPUTACIONAIS 


\subsection{Introdução}

Nesse capítulo são apresentados os resultados computacionais obtidos na resoliçào do QAP usando as implementações das meta-heurísticas pesquisadas.

Os testes foram realizados num microcomputador com processador Pentium II 400 MHz e 128 Mbytes de memória RAM, e as implementações foram realizadas em linguagem C.

As heuristicas foram testadas usando-se 17 exemplos numéricos do QAP, providos pelo site QAPLib (QAP Library) cujo endereço é http://www.opt.math.tu-graz.ac.at/qaplib/. Os exemplos numéricos são de tamanho 25 até 150, ou seja, exemplos considerados difíceis para algoritmos exatos. O tamanho de cada exemplo é indicado pelo número que consta de seu nome. Por exemplo, lipa90a é de tamanho 90, ou seja, apresenta 90 instalações a serem designadas a 90 localidades. Assim como lipa90a, todos os exemplos usados apresentam um número igual de instalações e localidades. Os exemplos numéricos foram escolhidos de acordo com a literatura pesquisada (Taillard, 1991, Merz e Freisleben, 1997, 1999, 2000) e os resultados obtidos são comparados com os melhores resultados encontrados até o momento.

As heurísticas foram executadas por um número fixo de iterações ou por um tempo computacional pré-fixado. A Tabela 5.1 descreve a nomenclatura utilizada em todas as tabelas desse capitulo.

\begin{tabular}{|l|l|}
\hline Exemplo & Nome do exemplo numérico \\
\hline Melhor_sol & Valor da f.o. para a melhor solução conhecida \\
\hline Gap & Diferença percentual entre a solução da heuristica e a Melhor_sol \\
\hline It_Melhor & Iteração onde foi encontrada a melhor solução pela heurística \\
\hline It_total & Quantidade total de iteraçōes \\
\hline T_melhor & Tempo onde foi encontrada a melhor solução pela heurística \\
\hline T_total & Tempo total de execução \\
\hline
\end{tabular}

Tabela 5.1. Descriçāo das legendas utilizadas na descrição dos resultados 
Note que T_total será indicado apenas nas tabelas onde a heuristica foi executada com critério de parada sendo quantidade de iterações, e It total apenas quando o critério de parada foi o tempo total de execução.

\subsection{Busca Tabu}

A seguir são apresentados os resultados obtidos com a implementação da Busca Tabu tratada em Taillard, 1991, para a resoluçào do QAP.

A Tabela 5.2 mostra os resultados da Busca Tabu ao final de 3000 iterações para cada exemplo. O Tempo Tabu foi atribuído aleatoriamente a partir de um intervalo fixado. Foram testados diferentes intervalos de valores para a atribuição do Tempo Tabu: [0.6n, 5n], [0.6n, n1], [0.6n, 2n], [5n, 10n] e [0.9(n-1), 1.1(n-1)+4]. A última faixa de intervalo foi a utilizada por Taillard, 1991. A que obteve melhores resultados foi a faixa [0.6n, 10n]. Conseqüentemente, os resultados mostrados na Tabela 5.2 são os obtidos a partir desse intervalo.

\begin{tabular}{|c|c|c|c|c|c|}
\hline Exemplo & Melhor_Sol & Gap & It_Melhor & T_melhor & T_total \\
\hline chr25a & 3796 & 10,06 & 671 & 0,16 & 0,63 \\
\hline bur26a & 5426670 & 0,09 & 29 & 0,02 & 0,68 \\
\hline Nug30 & 6124 & 0,56 & 563 & 0,20 & 0,92 \\
\hline kra30a & 88900 & 1,80 & 438 & 0,17 & 0,94 \\
\hline ste36a & 9526 & 3,11 & 657 & 0,32 & 1,35 \\
\hline tai60a & 7208572 & 1,92 & 436 & 0,65 & 4,07 \\
\hline tai80a & 13557864 & 1,52 & 505 & 1,43 & 7,84 \\
\hline tai100a & 21125314 & 1,37 & 1185 & 5,15 & 13,09 \\
\hline sko100a & 152002 & 0,61 & 1128 & 5,11 & 13,21 \\
\hline tai60b & 608215054 & 0,80 & 2942 & 4,43 & 4,60 \\
\hline tai80b & 818415043 & 3,74 & 2917 & 7,87 & 8,22 \\
\hline tai100b & 1185996137 & 6,48 & 1975 & 8,88 & 13,42 \\
\hline wil100 & 273038 & 0,37 & 1650 & 7,36 & 13,32 \\
\hline tho150 & 8133484 & 0,59 & 1919 & 22,81 & 35,82 \\
\hline tai150b & 498896643 & 3,43 & 2136 & 25,10 & 35,57 \\
\hline lipa9Ca & 360630 & 0,57 & 686 & 2,36 & 10,32 \\
\hline lipa90b & 12490441 & 0,00 & 527 & 1,99 & 1,99 \\
\hline Média & & $\mathbf{2 , 1 8}$ & $\mathbf{1 1 9 7}$ & $\mathbf{5 , 5 3}$ & $\mathbf{9 , 7 6}$ \\
\hline
\end{tabular}

Tabela 5.2. Resultados de Busca Tabu em 3000 iterações 
Uma das tentativas de variação usadas na configuração acima foi limitar a vizinhança visitada pela Busca Tabu, no momento da escolha do melhor movimento possível. Tanto a limitação da vizinhança em $\mathrm{n} / 2$ (metade do tamanho do exemplo), quanto em $0.75 \mathrm{n}$, não surtiram bons resultados, sendo que a limitação $\mathrm{cm} 0.75 \mathrm{n}$ foi melhor que em $\mathrm{n} / 2$.

$\mathrm{Na}$ Tabela 5.3, a seguir, são mostrados os resultados da mesma Busca Tabu, porém com o tempo de processamento sendo o critćrio de parada e não o número de iteraçòes. $O$ tempo máximo fixado foi de 5 n segundos.

\begin{tabular}{|c|c|c|c|c|c|}
\hline Exemplo & Melhor_Sol & Gap & It_Melhor & It_total & T_melhor \\
\hline chr25a & 3796 & 1,84 & 3244 & 606950 & 0,66 \\
\hline bur26a & 5426670 & 0,00 & 86112 & 86112 & 19,21 \\
\hline nug30 & 6124 & 0,00 & 4852 & 4852 & 1,44 \\
\hline kra30a & 88900 & 0,00 & 23932 & 23932 & 7,12 \\
\hline ste36a & 9526 & 0,00 & 46223 & 46223 & 20,16 \\
\hline tai60a & 7208572 & 1,19 & 124753 & 224225 & 166,81 \\
\hline tai80a & 13557864 & 0,88 & 149734 & 154471 & 387,66 \\
\hline tai100a & 21125314 & 0,77 & 17411 & 113493 & 76,65 \\
\hline sko100a & 152002 & 0,07 & 39032 & 114427 & 170,37 \\
\hline tai60b & 608215054 & 0,61 & 104486 & 225166 & 139,07 \\
\hline tai80b & 818415043 & 3,39 & 139859 & 156011 & 358,48 \\
\hline tai100b & 1185996137 & 5,93 & 16243 & 114797 & 70,69 \\
\hline wil100 & 273038 & 0,03 & 47070 & 114354 & 205,58 \\
\hline tho150 & 8133484 & 0,13 & 16333 & 63620 & 192,93 \\
\hline tai150b & 498896643 & 2,39 & 57364 & 63602 & 676,47 \\
\hline lipa90a & 360630 & 0,50 & 83122 & 131377 & 284,73 \\
\hline lipa90b & 12490441 & 0,00 & 527 & 527 & 1,78 \\
\hline Média & & 1,04 & 56488 & 132008 & 163,52 \\
\hline
\end{tabular}

Tabela 5.3 - Resultados de Busca Tabu em $5 n$ segundos

\subsection{Algoritmos Genéticos}

A seguir são apresentados os resultados obtidos com a implementação de Algoritmos Genéticos, apresentados no capítulo anterior, para a resolução do QAP. 
A Tabela 5.4. apresenta os resultados do Algoritmo Genético com uma populaçào de 40 individuos e uma quantidade de cruzamentos igual a 20 (tamanho da populaçào/2). Esses são os parâmetros para os quais o algoritmo genético obteve os melhores resultados.

\begin{tabular}{|c|c|c|c|c|c|}
\hline Exemplo & Melhor_Sol & Gap & It_Melhor & It_total & T_melhor \\
\hline chr25a & 3796 & 49,42 & 16763 & 18048 & 116,08 \\
\hline bur26a & 5426670 & 0,26 & 17462 & 17648 & 128,64 \\
\hline nug30 & 6124 & 4,18 & 10323 & 17892 & 86,50 \\
\hline kra30a & 88900 & 4,90 & 15988 & 17859 & 134,27 \\
\hline ste36a & 9526 & 14,59 & 14520 & 15985 & 163,50 \\
\hline tai60a & 7208572 & 7,08 & 13657 & 14161 & 289,30 \\
\hline tai80a & 13557864 & 6,48 & 11129 & 11359 & 391,90 \\
\hline tai100a & 21125314 & 7,34 & 9090 & 10452 & 434,98 \\
\hline sko100a & 152002 & 6,39 & 9361 & 10438 & 448,50 \\
\hline tai60b & 608215054 & 6,37 & 13034 & 13759 & 284,01 \\
\hline tai80b & 818415043 & 10,08 & 11905 & 11931 & 399,14 \\
\hline tai100b & 1185996137 & 11,36 & 9757 & 10257 & 475,64 \\
\hline wil100 & 273038 & 2,87 & 10177 & 10295 & 494,39 \\
\hline tho150 & 8133484 & 8,17 & 7573 & 7829 & 725,67 \\
\hline tai150b & 498896643 & 11,19 & 7811 & 7831 & 748,18 \\
\hline lipa90a & 360630 & 1,06 & 10809 & 11235 & 432,94 \\
\hline lipa90b & 12490441 & 24,41 & 7683 & 11241 & 307,63 \\
\hline Média & & 10,36 & 11590 & 12836 & $\mathbf{3 5 6 , 5 4}$ \\
\hline
\end{tabular}

Tabela 5.4. Resultados de GA em $5 n$ segundos

A Tabela 5.5, mostra a média de resultados, alterando-se o tempo máximo de execução de 5 n segundos para 50n segundos:

\begin{tabular}{|c|c|c|c|c|}
\hline T_total & Gap & It_Melhor & It_total & T_melhor \\
\hline $5 \mathrm{n}$ & 10,36 & 11590 & 12836 & 356,54 \\
\hline $50 \mathrm{n}$ & 7,56 & 87920 & 117048 & 3434,96 \\
\hline
\end{tabular}

Tabela 5.5. Resultados médios de GA em $5 n$ e $50 n$ segundos

A Tabela 5.6 apresenta os resultados médios com duas diferentes estratégias de mutação. A princípio o operador de mutação é utilizado apenas quando a população converge (M1). Ėm M2 o operador de mutação é utilizado sem a necessidade da população ter 
convergido. Nesse último caso, a cada geração foram realizadas 40 mutações em indivíduos escolhidos aleatoriamente.

\begin{tabular}{|c|c|c|c|c|c|}
\hline Mutaçāo & T_total & Gap & It_Melhor & It_total & T_melhor \\
\hline \multirow{2}{*}{ M1 } & $5 n$ & 10,36 & 11590 & 12836 & 356,54 \\
\cline { 2 - 6 } & $50 n$ & 7,56 & 87920 & 117048 & 3434,96 \\
\hline \multirow{2}{*}{ M2 } & $5 n$ & 9,33 & 5511 & 5933 & 362,33 \\
\cline { 2 - 6 } & $50 n$ & 6,24 & 46315 & 52554 & 3563,51 \\
\hline
\end{tabular}

Tabela 5.6. Resultados médios de GA usando diferentes estratégias para mutação

A estratégia Ml é a apresentada por Merz e Freisleben, 1999, e foi a melhor estratégia para o algoritmo memético, que possui uma busca local. Já a estratégia M2 obteve mclhores resultados no algoritmo genético, indicando a necessidade de uma maior aplicação do operador de mutação quando não é utilizada uma Busca Local.

\subsection{Algoritmos Meméticos}

A seguir são apresentados os resultados obtidos pclos dois algoritmos meméticos. Na Tabela 5.7 estão os resultados obtidos pelo AM, utilizando-se a busca local proposta por Merz e Freisleben, 1999 (MBL). Na Tabela 5.8 estão indicados os resultados do AM utilizando-se como busca local a busca tabu de Taillard, 1991 (MBT). Em ambas, o critério de parada foi o tempo de execução igual a 5 n segundos. 


\begin{tabular}{|c|c|c|c|c|c|}
\hline Exemplo & Melhor_Sol & Gap & It_Melhor & It_total & T_melhor \\
\hline Chr25a & 3796 & 0,00 & 43 & 43 & 3,83 \\
\hline Bur26a & 5426670 & 0,08 & 16 & 4211 & 0,90 \\
\hline Nug30 & 6124 & 0,07 & 16 & 3343 & 2,31 \\
\hline Kra30a & 88900 & 1,35 & 32 & 1104 & 4,52 \\
\hline Ste36a & 9526 & 0,00 & 47 & 47 & 11,32 \\
\hline Tai60a & 7208572 & 1,47 & 86 & 316 & 85,54 \\
\hline Tai80a & 13557864 & 1,01 & 103 & 173 & 242,91 \\
\hline Tai100a & 21125314 & 1,05 & 100 & 102 & 493,20 \\
\hline sko100a & 152002 & 0,14 & 72 & 102 & 355,80 \\
\hline tai60b & 608215054 & 0,02 & 62 & 861 & 60,19 \\
\hline tai80b & 818415043 & 0,57 & 138 & 153 & 362,99 \\
\hline tai100b & 1185996137 & 0,16 & 75 & 96 & 392,79 \\
\hline wil100 & 273038 & 0,23 & 55 & 101 & 278,06 \\
\hline tho150 & 8133484 & 0,39 & 40 & 41 & 744,15 \\
\hline tai150b & 498896643 & 0,80 & 45 & 45 & 766,58 \\
\hline lipa90a & 360630 & 0,47 & 128 & 130 & 443,56 \\
\hline lipa90b & 12490441 & 0,00 & 32 & 32 & 115,31 \\
\hline Média & & 0,46 & 64,12 & 641,18 & 256,70 \\
\hline
\end{tabular}

Tabel; 5.7. Resultados do MBL (usando a busca local de Mcrz e Freisleben, 1999)

\begin{tabular}{|c|c|c|c|c|c|}
\hline Exemplo & Melhor_Sol & Gap & It_Melhor & It_total & T_melhor \\
\hline chr25a & 3796 & 0,00 & 16 & 16 & 26,82 \\
\hline bur26a & 5426670 & 0,00 & 0 & 0 & 1,21 \\
\hline nug30 & 6124 & 0,00 & 6 & 6 & 6,74 \\
\hline kra30a & 88900 & 0,00 & 4 & 4 & 9,93 \\
\hline ste36a & 9526 & 0,00 & 7 & 7 & 25,72 \\
\hline tai60a & 7208572 & 0,85 & 25 & 28 & 270,36 \\
\hline tai80a & 13557864 & 0,79 & 19 & 20 & 393,87 \\
\hline tai100a & 21125314 & 0,72 & 15 & 15 & 529,37 \\
\hline sko100a & 152002 & 0,15 & 15 & 15 & 526,17 \\
\hline tai60b & 608215054 & 0,10 & 13 & 28 & 140,33 \\
\hline tai80b & 818415043 & 0,18 & 16 & 20 & 330,26 \\
\hline tai100b & 1185996137 & 0,43 & 14 & 15 & 490,34 \\
\hline wil100 & 273038 & 0,12 & 15 & 15 & 525,70 \\
\hline tho150 & 8133484 & 0,48 & 8 & 8 & 802,80 \\
\hline tai150b & 498896643 & 1,48 & 8 & 8 & 803,81 \\
\hline lipa90a & 360630 & 0,52 & 15 & 17 & 411,52 \\
\hline lipa90b & 12490441 & 0,00 & 3 & 3 & 63,53 \\
\hline Média & & 0,34 & 11,71 & 13,24 & 315,20 \\
\hline
\end{tabular}

Tabela 5.8. Resultados do MBT (usando como a busca local a Busca Tabu de Taillard, 1991). 
Observe pelas tabela 5.7 e 5.8, que a incorporação de Busca Tabu como a busca local dentro do algoritmo memético resultou em melhores resultados. Note também que o número total de iterações (geraçôes) no MBT é de 13,24 enquanto que no MBL é de 641,18, indicando que a Busca Tabu é um processo mais intenso e, conseqüentemente, mais eficaz, como mos ram os resultados.

\subsection{Comparação entre as meta-heurísticas}

As Tabelas 5.9 e 5.10 reúnem os resultados obtidos pelas diferentes heurísticas. A Tabela 5.9 apresenta os valores de gap obtidos em cada exemplo, e a Tabela 5.10 os resultados médios.

\begin{tabular}{|c|c|c|c|c|}
\hline Exemplo & BT & GA & MBL & MBT \\
\hline chr25a & 1,84 & 49,42 & 0,00 & 0,00 \\
\hline bur26a & 0,00 & 0,26 & 0,08 & 0,00 \\
\hline rır30 & 0,00 & 4,18 & 0,07 & 0,00 \\
\hline kra30a & 0,00 & 4,90 & 1,35 & 0,00 \\
\hline ste36a & 0,00 & 14,59 & 0,00 & 0,00 \\
\hline tai60a & 1,19 & 7,08 & 1,47 & 0,85 \\
\hline tai80a & 0,88 & 6,48 & 1,01 & 0,79 \\
\hline tai100a & 0,77 & 7,34 & 1,05 & 0,72 \\
\hline sko100a & 0,07 & 6,39 & 0,14 & 0,15 \\
\hline tai60b & 0,61 & 6,37 & 0,02 & 0,10 \\
\hline tai80b & 3,39 & 10,08 & 0,57 & 0,18 \\
\hline tai100b & 5,93 & 11,36 & 0,16 & 0,43 \\
\hline wil100 & $\mathbf{0 , 0 3}$ & 2,87 & 0,23 & 0,12 \\
\hline tho150 & $\mathbf{0 , 1 3}$ & 8,17 & 0,39 & 0,48 \\
\hline tai150b & 2,39 & 11,19 & $\mathbf{0 , 8 0}$ & 1,48 \\
\hline lipa90a & 0,50 & 1,06 & $\mathbf{0 , 4 7}$ & 0,52 \\
\hline lipa90b & $\mathbf{0 , 0 0}$ & 24,41 & $\mathbf{0 , 0 0}$ & $\mathbf{0 , 0 0}$ \\
\hline Média & $\mathbf{1 , 0 4}$ & $\mathbf{1 0 , 3 6}$ & $\mathbf{0 , 4 6}$ & $\mathbf{0 , 3 4}$ \\
\hline
\end{tabular}

Tabela 5.9. GAPs obtidos por cada heuristica para cada exemplo 


\begin{tabular}{|c|c|c|c|c|}
\hline Heuristica & Gap & It_Melhor & It_total & T_melhor \\
\hline BT & 1,04 & 56488 & 132008 & 163,52 \\
\hline GA & 10,36 & 11590 & 12836 & 356,54 \\
\hline MBL & 0,46 & 64,12 & 641,18 & 256,70 \\
\hline MBT & 0,34 & 11,71 & 13,24 & 315,20 \\
\hline
\end{tabular}

Tabela 5.10. Resultados médios obtidos por cada heuristica

Em termos médios a heuristica MBT conseguiu obter os melhores resultados. Em alguns exemplos, a heurística MBL ou a BT conseguiu superar a MBT, mas nunca de maneira significativa. O GA se mostrou extremamente ineficaz quando utilizado sem uma busca local.

O algoritmo memético sendo utilizado juntamente com Busca Tabu já sc mostrou eficaz na resolução de outros problemas, como visto em Berretta e Moscato, 1999. 
6. CONCLUSÃO 
Esse trabalho apresentou uma avaliaçào de algumas técnicas meta-heuristicas para a resolução do Problema de Designação Quadrática (QAP). Ainda não se conhece um algoritmo eficiente que apresente resolução exata desse problema, pois ele pertence à classe de problemas NP-dificil.

As meta-heurísticas implementadias foram Busca Tabu, Algoritmo Genético e Algoritmo Memético, sendo que este último foi implementado em duas versōes, uma utilizando Busca Tabu e outra utilizando uma Busca Local, ambas encontradas na literatura.

O algoritmo de Busca Tabu implementado foi desenvolvido por Taillard, 1991. Um algoritmo memético implementado foi o desenvolvido por Merz e Freisleben, 1999. O outro foi idêntico, porém substituindo-se a Busca Local utilizada por Merz e Frcisleben, 1999, pcla Busca Tabu de Taillard, 1991. Além disso, foram realizados testes com o algoritmo memético sem nenhuma busca local, ou seja, um algoritmo genético.

As heurísticas foram testadas em um grupo de exemplos encontrados na literatura pesquisada. A Tabela abaixo apresenta os gaps médios obtidos por cada uma das heuristicas:

\begin{tabular}{|c|c|c|c|}
\hline BT & GA & MBL & MBT \\
\hline 1,04 & 10,36 & 0,46 & 0,34 \\
\hline
\end{tabular}

Pode-se atestar a superioridade do algoritmo memético para a resolução desse problema. Além disso, a utilização de Busca Tabu como a Busca Local dentro do Algoritmo Memético se mostrou a estratégia mais eficaz.

Como proposta pode-se considerar a implementação de elementos mais sofisticados nos algoritmos meméticos, como por exemplo, a estruturação da população como realizada em Berretta e Moscato, 1999. Também se pode testar outros operadores de cruzamento e mutação, e diferentes combinações de buscas locais no Algoritmo Memético. 
7. REFERÊNCIAS BIBLIOGRÁFICAS 
Beasley, J. E., 1993, Lagrangean Relaxation, em Modern heuristic techniques for combinatorial problems, C.R.Reeves, ed, 243-303, Blackwell Scientific Publications.

Berretta, R. e Moscato, P., 1999, The number partitioning problem: An open challenge for evolutionary computation?, em New Ideas in Optimization, D. Come, F. Glover, e M. Dorigo, ed, McGraw-Hill.

Burkard, R. E. e Çela, E., 1997, Quadratic and Three-Dimensional Assignments: An Annotated Bibliography, Annotated Bibliographies in Combinatorial Optimization, M. Dell'Amico, F. Maffioli e S.Martello, eds., Wiley, Chichester, pp. 373-392.

Dell'Amico M., Maffioli, F. e Martello, S., 1997, Annotated Bibliographies in Combinatorial Optimization, Wiley, Chichester.

Diaz, A., Glover, F., Ghaziri, H. M., Velarde, J. L. G., Laguna, M., Moscato,. P. e Tsen, F. T., 1996, Optimización Heurística y Redes Neuronales, Editorial Paraninfo, Espanha.

Elshafei, 1977, Hospital Layout as a Quadratic Assignment Problem, Operations Research Quarterly, vol. 28, no. 1, 167-179.

Garey, M. R. e Johnson, D. S., 1979, Computers and 'atractability: A Guid z to the Thun of NP-Completeness, W. H. Freeman.

Gcro, J. S., Kazakov, V. and Schnier, T., 1997, Genetic engineering and design problems, in D. Dasgupta and Z. Michalewicz (eds), Evolutionary Algorithms in Engineering Applications, Springer Verlag, Berlin, pp.47-68.

Glover, F. e Lag.na, M. 1997, Tabu Search, Klumer Academic Publishers Norwell, Massachussetts.

Goldberg, D. E., 1989, Genetic Algoritms in Search, Optimization, and Machine Learning. Addison Wesley, Reading.

Holland, J. H., 1975, Adaption in Natural and Artificial Systems, An introductory analysis with application to biology, control, and artificial intelligence, The University of Michigan Press, Ann Arbor, USA.

Jünger, M., Martin, A., Reinelt, G. e Weismantel, R., 1994, Quadratic 0/1-Optimization and a Decomposition Approach for the Placement of Electronic Circuits , Mathematical Programming, 63, 257-280. 
Larrañaga, P., Kuijpers, C. M. H., Murga, R. H., Inza, I. e Dizdarevic, S., 1999, Genetic Algorithms for the Travelling Salesman Problem: A Review of Representations and Operators. Artificial Intelligence Review 13(2): 129-170.

Li, Y., Pardalos, P.M., Ramakrishnan, K.G. e Resende, M.G.C., 1994, Lower bounds for the quadratic assignment problem, Annals of Operations Research, 50, pp 387.411.

MAs Home Page, 2002, http://ww'densis. fee.unicamp.br $\sim$ moscato memetic home.html

Merz, P. e Freisleben, B., 1997, A Genetic Local Search Approach to the Quadratic Assignment Problem, Proceedings of the Seventh International Conference on Genetic Algorithms (ICGA'97), Thomas Bäck, ed., Morgan Kaufmann, pp. 465-472.

Merz, P. e Freisleben, B., 1999, A Comparison of Memetic Algorithms, Tabu Search, and Ant Colonies for the Quadratic Assignment Problem, Proceedings of the 1999 International Congress of Evolutionary, Computation (CEC'99), IEEE Press, pp. 20632070 .

Merz, P. e Freisleben, B., 2000, Fitness Landscape Analysis and Memetic Algorithms for the Quadratic Assignment Problem, IEEE Transactions on Evolutionary Computation, vol. 4 , no. 4 , pp. $337-352,2000$.

Merz, P. e Freisleben, B., 1996a, A Genetic Local Search Algorithm for Solving Symmetric and Asymmetric Traveling Salesman Problems, Proceedings of the 1996 IEEE International Conference on Evolutionary Computation, IEEE Press, pp. 616-621.

Merz, P. e Freisleben, B., 1996b, New Genetic Local Search Operators for the Traveling Salesman Problem, Proceedings of the 4th Conference on Parallel Problem Solving from Nature - PPSN IV, H.-M. Voigt, W. Ebeling, I. Rechenberg, H.-P. Schwefel, eds., Volume 1141 of Lecture Notes in Computer Science, Springer, pp. 890-899.

Moscato, P. e Norman, M., 1989, On Evolution, Search, Optimization, Genetic Algorithms and Martial Arts: Towards Memetic Algorithms, Caltech Concurrent Computation Program, Report. 790.

Moscato, P., 1989, On Evolution, Search, Optimization, Genetic Algorithms and Martial Arts: Towards Memetic Algorithms, P. Moscato, Caltech Concurrent Computation Program, C3P Report 826. 
Moscato, P., 1999, Memetic Algorithms: a short introduction, capitulo $14 \mathrm{em}$ New Ideas in Optimisation, D. Corne, F. Glover, and M. Dorigo, eds., McGraw-Hill.

Nemhauser, G. L. e Wolsey, L. A., 1988, Integer and Combinatorial Optimization. John Wiley \& Sons.

Oliver, I., Smith, D., e Holland, J., 1987, A study of permutation crossover operators on the traveling salesman problem. In Grefenstette, J. J., editor, Genetic Algorithms And Their Applications: Proceedings of the Second Internal Conference on Genetic Algorithms, 224-230, Hilsdale, New Jersey, Hove and London. Lawrence Erlbaum Associates, Publishers.

Reeves, C., 1993, Modern heuristic techniques for combinatorical problems, John Wiley \& Sons, Inc.

Shorin-Kapov, J., 1994, Extensions of Tabu Search Adaptation to the Quadratic Assignment Problem, Computers and Operations Research, Vol.21(8), 855-865.

Taillard, E., 1991, Robust Taboo Search for the Quadratic Assignment Problem, Parallel Computing, 17, pp. 443--445.

Tate, D. M. e Smith, A. E., 1995, A genetic approach to the quadratic assignment problem, Computers and Operations Reseach, vol. 22, no.1, 73-83.

Wilhelm, M. e Ward, T., 1987, Solving quadratic assignment problems by simulated annealing, IIE Transactions, 19:107-119, 15. 